\title{
Attitudes, beliefs, and practices of key opinion leaders (KOL) and providers about emergency contraception (EC) in Senegal
}

\author{
Babacar Mane \\ Population Council \\ Saumya RamaRao \\ Population Council \\ Martha Brady \\ Population Council \\ Fatou Bintou Mbow \\ Ababacar Thiam
}

Follow this and additional works at: https://knowledgecommons.popcouncil.org/departments_sbsr-rh

Part of the International Public Health Commons, Maternal and Child Health Commons, Obstetrics and Gynecology Commons, Social and Behavioral Sciences Commons, and the Women's Health Commons

How does access to this work benefit you? Let us know!

\section{Recommended Citation}

Mane, Babacar, Saumya RamaRao, Martha Brady, Fatou Bintou Mbow, and Ababacar Thiam. 2012.

"Attitudes, beliefs, and practices of key opinion leaders (KOL) and providers about emergency contraception (EC) in Senegal," Final survey report. Dakar: Population Council. 


\section{(P) Population Council}

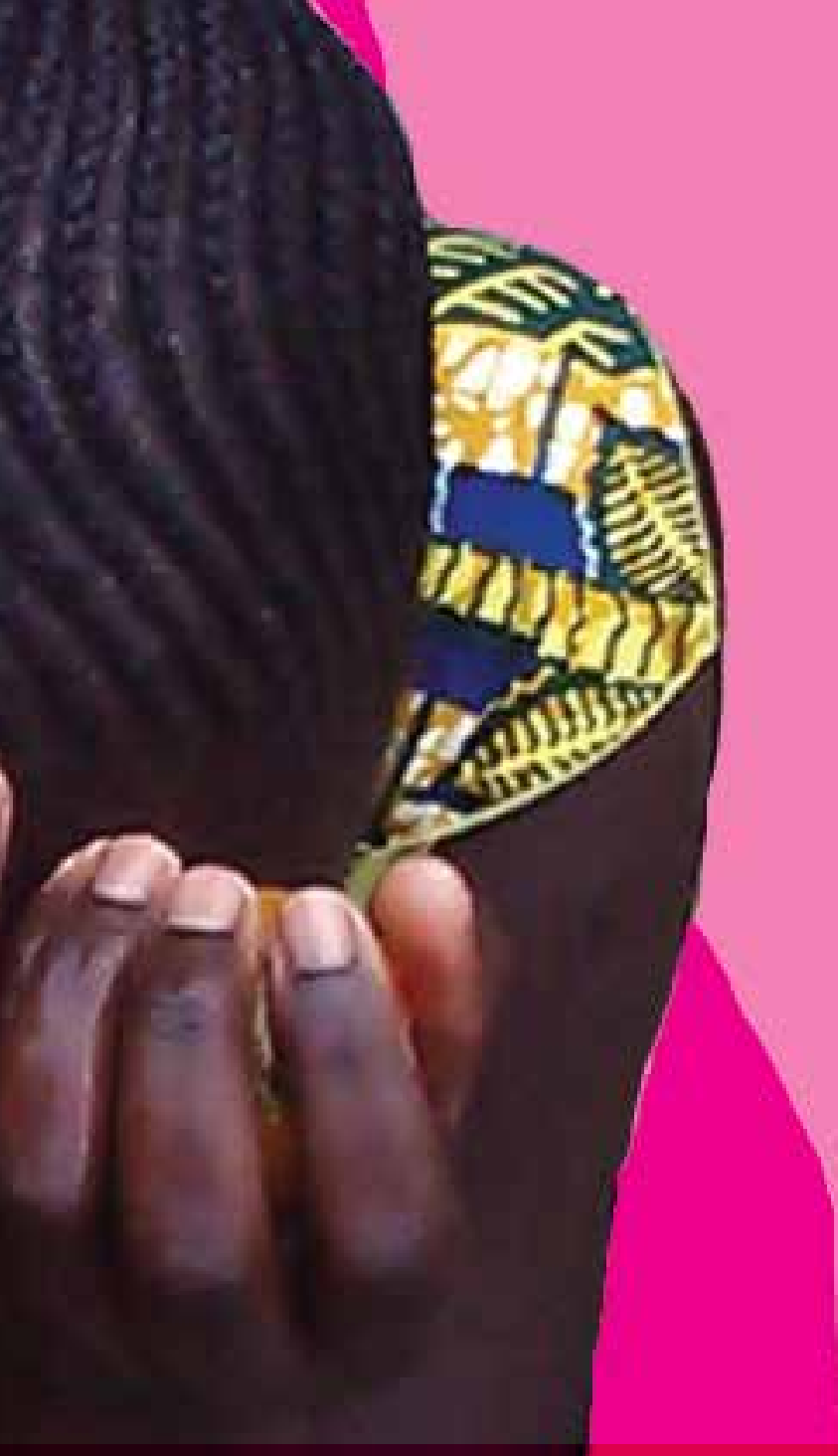

\section{ATIITUDES, BELIEFS, AND PRATICES}

OF KEY OPINION LEADERS (KOL) AND PROVIDERS ABOUT EMERGENCY CONTRACEPTION (EC) IN SENEGAL 


\section{WHERE WE WORK?}

THE POPULATION COUNCIL HAS 18 OFFICES IN 16 COUNTRIES.

WE CARRY OUT RESEARCH AND PROGRAMS AND STRENGTHEN

THE SKILLS OF LOCAL RESEARCHERS AROUND THE WORLD.

BOLDFACE NAMES INDICATE COUNTRIES IN WHICH THE COUNCIL HAS AN OFFICE.

$\triangle$ INDICATE WORK IN HIV AND AIDS.

INDICATE WORK IN POVERTY, GENDER, AND YOUTH.

— INDICATE WORK IN REPRODUCTIVE HEALTH.

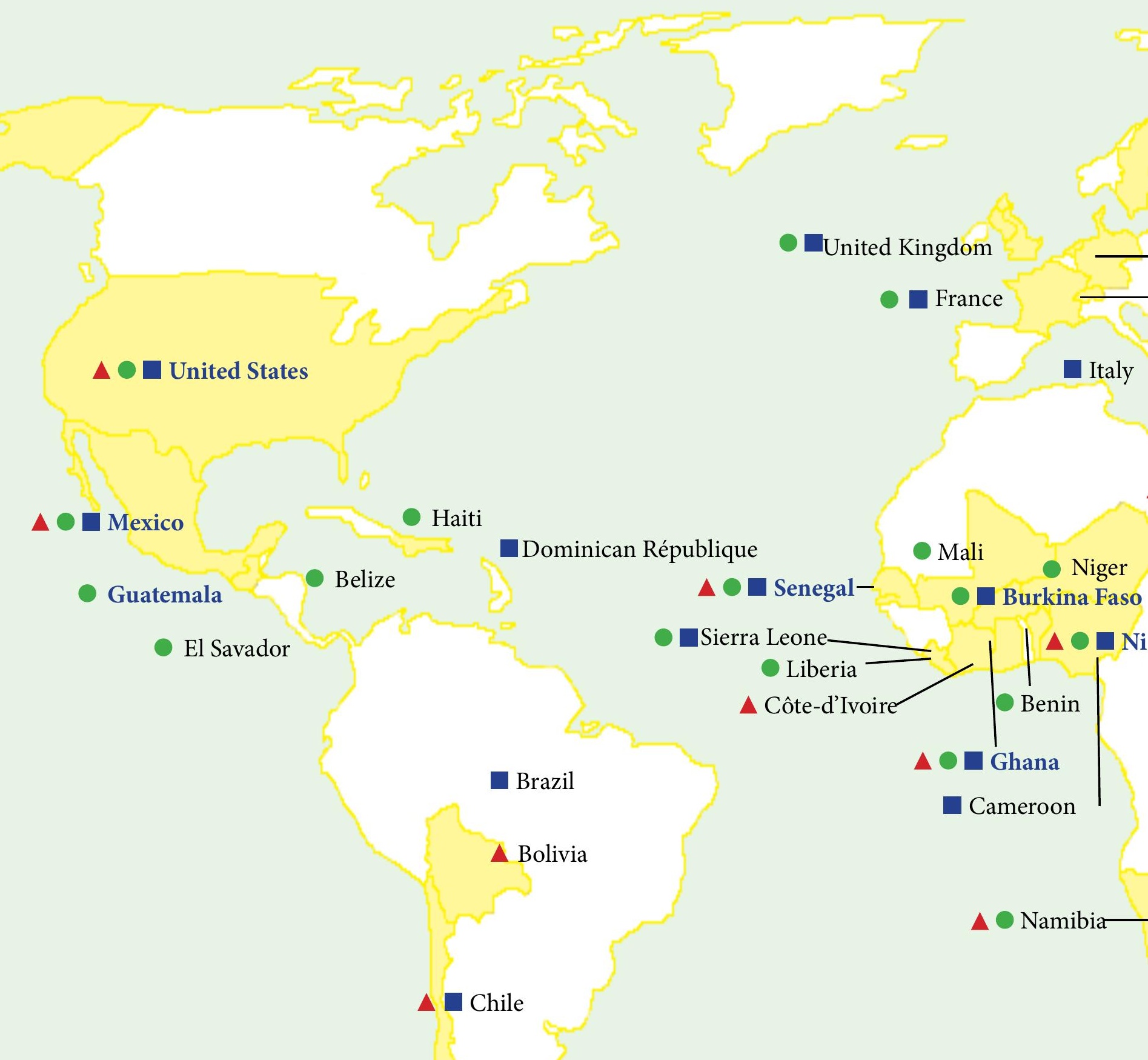

Argentina 
Sweden

Germany

Switzerland

$\longrightarrow$ Syria

China

口 Japan

- Pakistan

Egypt

Sudan

South Sudan

geria

$\triangle$ Ethiopia

- 1 Uganda

$\triangle O \square$ Kenya

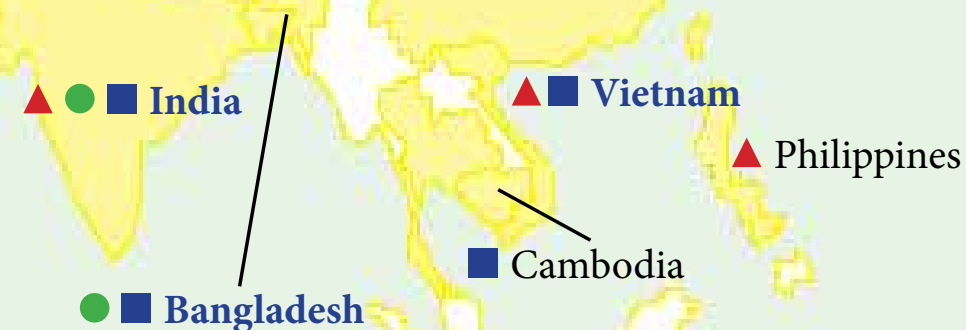

Bangladesh

$\triangle \bigcirc$ Zambia $^{\wedge} \bigcirc \mathrm{Tanzania}$

$\triangle$ Malawi

$\triangle$ Zimbabwe

Y $\bigcirc$ Swaziland

Australia

1

$\triangle$ South Africa 


\section{(2) Population Council}

\section{ATTITUDES, BELIEFS, AND PRATICES \\ OF KEY OPINION LEADERS (KOL) AND PROVIDERS \\ ABOUT EMERGENCY CONTRACEPTION (EC) IN SENEGAL}

Babacar Mané

Saumya Ramarao

Martha Brady

Fatou Bintou Mbow

Ababacar Thiam

Avril, 2012 


\section{Table of Contents}

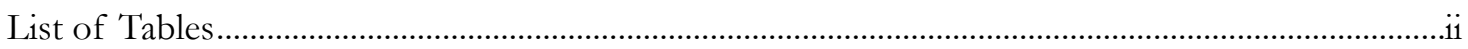

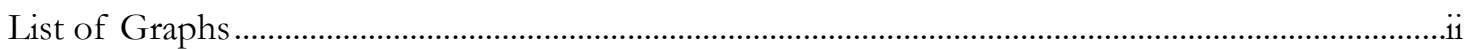

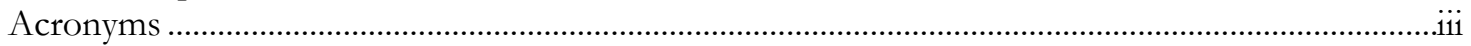

Acknowledgements ........................................................................................................................

Summary

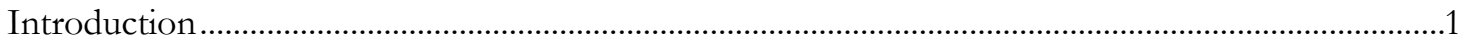

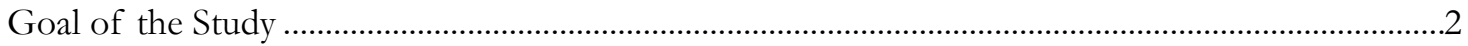

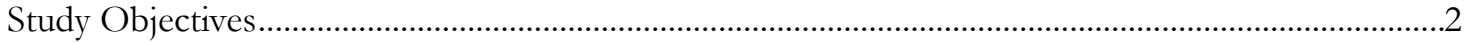

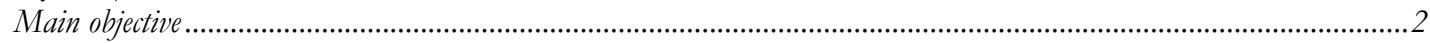

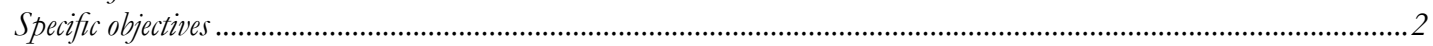

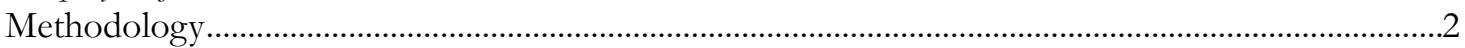

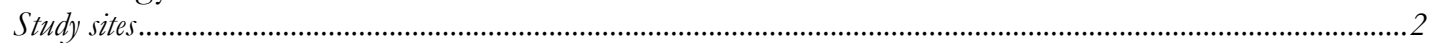

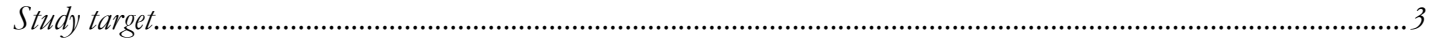

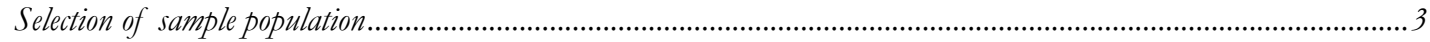

Data collection tools and issues explored ..........................................................................................................

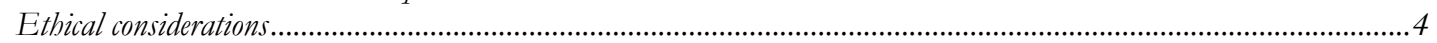

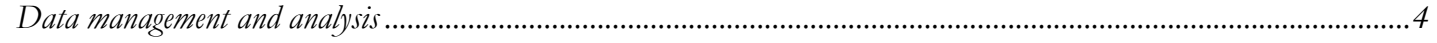

Assessment of Data Collection .....................................................................................................

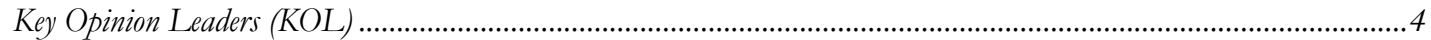

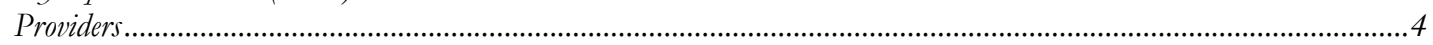

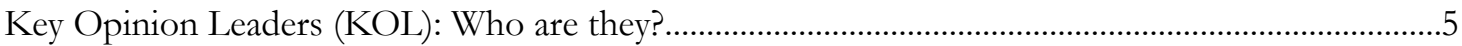

Product Knowledge .....................................................................................................................6

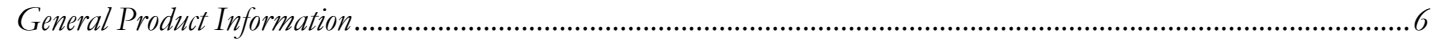

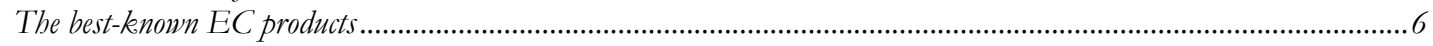

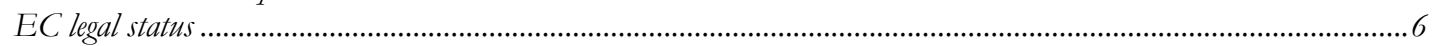

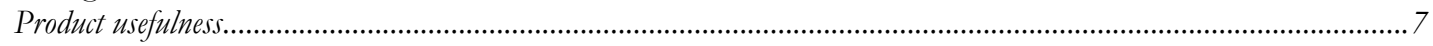

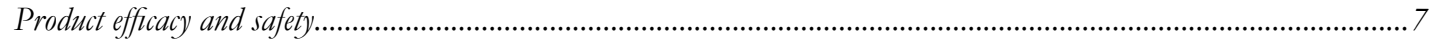

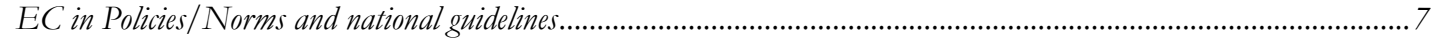

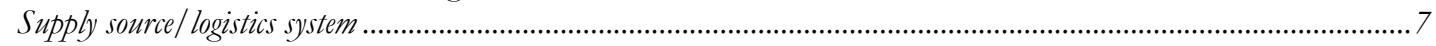

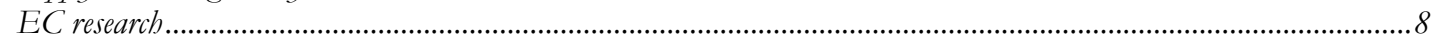

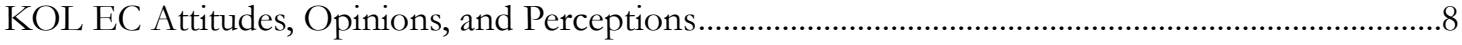

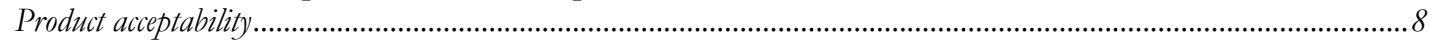

EC can contribute to FP repositioning............................................................................................................ 9

Perceptions of provider attitudes toward the product and its acceptability ................................................................. 9

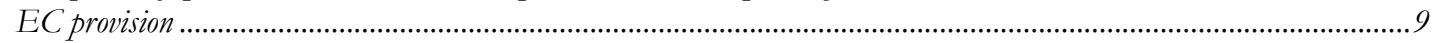

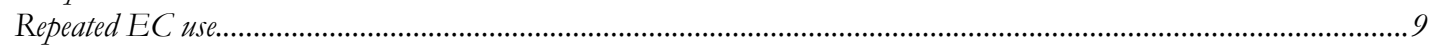

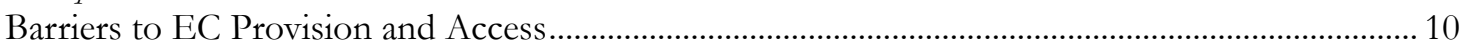

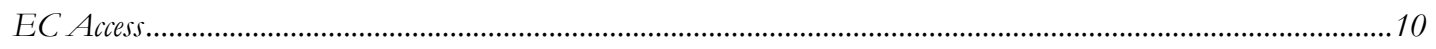

Barriers to EC Provision ……………………………………………………………………………………...

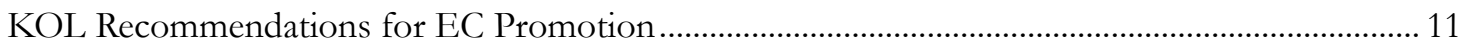

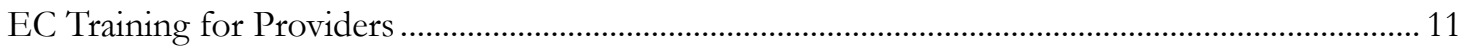

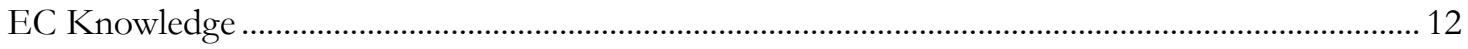

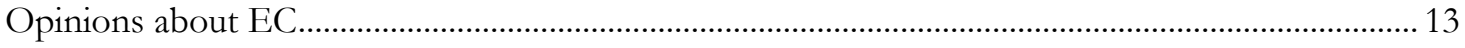

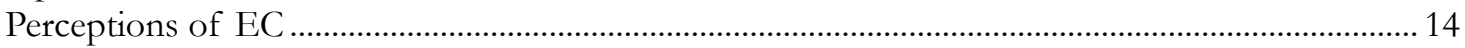

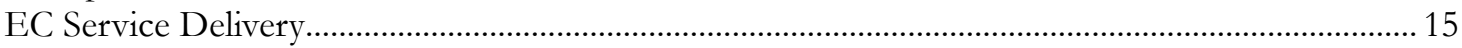

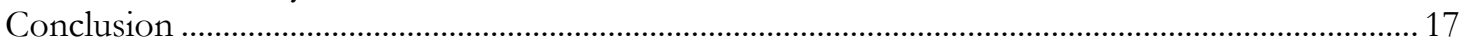

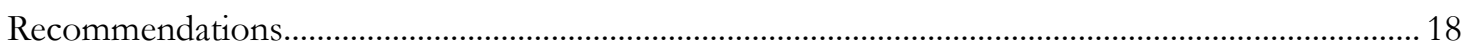

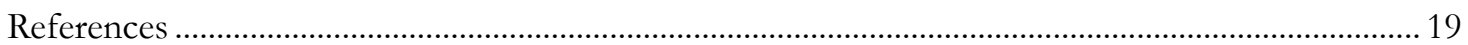




\section{Liste des Tableaux}

Table 1: Distribution of KOL by profile

Table 2: Distribution of Service Delivery Points by type .........................................................................................................

Table 3: Distribution of providers by professional category ……........................................................................................ 5

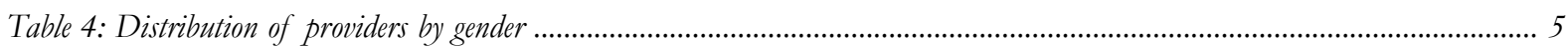

Table 5: Distribution of providers by age and EC experience …............................................................................................. 5

Table 6: Percentage of providers currently offering EC by professional category and region ……................................................. 5

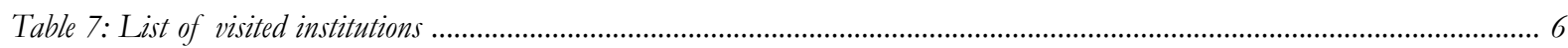

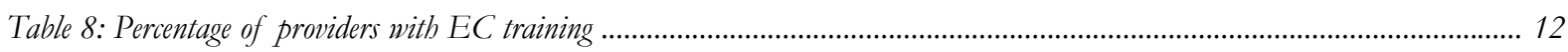

Table 9: Percentage of providers with EC training by professional category ……...................................................................... 12

Table 10: Percentage of providers understandings of the EC mechanism of action ................................................................. 12

Table 11: Percentage of providers who think EC is a form of abortion .................................................................................. 13

Table 12: Distribution of providers by opinions on where EC should be offered ……................................................................. 14

Table 13: Distribution of providers by opinions on age of EC users ........................................................................................ 14

Table 14: Distribution of providers by opinions on number of times a woman can use EC per year .......................................... 115

Table 15: Distribution of providers by perceptions of women who use EC................................................................................ 15

Table 16: Distribution of providers by services normally provided to EC................................................................................... 15

\section{Liste des Graphiques}

Graph 1: Proportion of providers previously trained in FP counseling by qualification .............................................................. 11

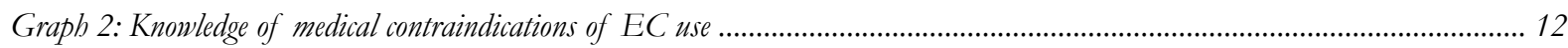

Graph 3: Distribution of providers by knowledge of EC eligibility criteria ........................................................................... 13

Graph 4: Distribution of providers by opinions on certain conditions of EC provision …........................................................... 13

Graph 5: Distribution of providers by opinions on type of providers authorized to supply EC …….......................................... 13

Graph 6: Distribution of providers by opinion on when EC should be used ............................................................................ 14

Graph 7: Types of EC products normally provided to users ................................................................................................... 15

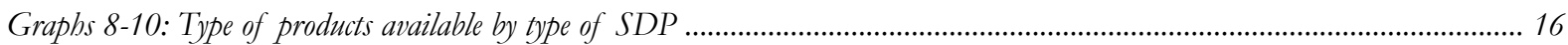




\section{Acronyms}

ACDEV Action for Development

ASBEF Association Sénégalaise pour le Bien Etre Familial

CBO Community Based Organization

CCA Counseling Centers for Adolescents

CEFOREP Centre de Formation et de Recherche en santé de la Reproduction/ Center for Training and Research in Reproductive Health

COUD Centre des CEuvres Universitaires de Dakar/ Social Center for Dakar University

DRH Division for Reproductive Health

EC/ECP Emergency Contraception/

Emergency Contraceptive Pills

FAWE Forum for African Women Educationalist

FP Family Planning

IEC Information, Education and Communication

ISSU Initiative sénégalaise de santé Urbaine/

Urban Reproductive Health Initiative in Senegal

KOL Key Opinions Leaders

NGO Non Governmental Organisation

PNA National Supply Pharmacy

PNP Politics, Norms and Protocols

SDP Services Delivery Point

STI Sexual Transmitted Diseases 


\title{
Acknowledgements
}

Population Council extends its warm thanks to those who contributed to the realization of this study.

Thanks go to our partners at the Ministry of Health and Social Action, especially to the Division of Reproductive Health (DRH) and to the Division of Health Research (DHR), who facilitated the implementation of data collection in the field.

We express our deep gratitude to officials at the institutions that we visited, especially to the regional and district head doctors in Dakar, Thiès, and Mbour; the officials at clinics, private pharmacies, and NGOs (ASBEF, FAWE, ACDEV, Siggil Jiggen Network, etc.); the officials at national institutions (Parliament, Ministry of National Education Through the Division of Medical Inspection, the Ministry of Youth Through the Project for the Promotion of Youth, etc.); our partners in development (USAID, UNFPA, WHO, etc.); the members of professional networks (Association of Women Lawyers, Islam and Population Network, Network of Journalists, Order of Pharmacists, Order of Doctors, etc.); and the members of community-based organizations (Action Movement for Youth, Synergie Banlieue, etc.) for their willingness to participate and for their positive contributions.

We also extend heartfelt thanks to everyone who took the time to participate in our interviews.

We would like to recognize here the professionalism of researchers and data collectors who demonstrated unwavering commitment to the success of this study.

All institutions and individuals who were able to make a valuable contribution to this study should be aware of our sincere recognition.

This study was made possible by funds from the Bill \& Melinda Gates Foundation.

\section{Dr Nafissatou DIOP}

\author{
Population Council Sénégal \\ Country Director
}




\section{Summary}

More often known as the "morning after" pill, the Emergency Contraceptive Pill (ECP) has been used for over 30 years throughout the world as a method for preventing unwanted pregnancy. EC is a unique contraceptive preventing unwanted pregnancy after unprotected or poorly protected sexual intercourse.

Access to EC is an important part of overall family planning (FP) strategies, especially in contexts where the magnitude of unwanted pregnancies, violence, sexual abuse, and their consequences (unsafe abortions, infanticide) is high. The issue calls for greater attention by national stakeholders.

In Senegal, initiatives for mainstreaming EC in the FP program are fairly recent. EC was included in Senegal's FP program in the mid 2000s, and by 2007-2008 it was included in the FP program's policies and guidelines. Service statistics indicate, however, that ECP distribution through the public sector is very low $(<2 \%)$. While most users access ECPs through the private sector, the volume of sales is not clear, due to the absence of an operational information system of EC distribution through pharmacies.

In an effort to strengthen EC provision in Senegal and reposition EC within the FP program, Population Council conducted a study in collaboration with the Reproductive Health Division (RHD) of the Ministry of Health, Senegal to document the positions and perceptions of Key Opinion Leaders (KOLs) who can shape the policy and program framework ; as well as documenting providers' attitudes, beliefs, and practices regarding EC. Support for this study was provided by the International Consortium for Emergency Contraception, as part of a three-country project also including Nigeria and India.

\section{Study Objectives}

\section{Global objective}

The study's overall objective is collecting information from KOLs and providers about their EC knowledge, attitudes, and practices, and understanding their options and perceptions that may influence EC policies and programs.

\section{Specific objectives}

- Documenting providers' EC attitudes, beliefs, and practices, including the issue of repeat use ;

- Capturing KOL's views and perceptions about EC policy and program issues ;

- Collecting suggestions and recommendations for establishing appropriate interventions for repositioning $\mathrm{EC}$ in public and private health sectors.

\section{Methodology}

\section{Study sites}

The study was conducted in August and September 2011 in Dakar and Thiès urban areas targeted by the "Urban Reproductive Health Initiative in Senegal" (ISSU) project, funded by the Bill and Melinda Gates Foundation.

\section{Respondents}

The study collected information from two types of respondents: KOLs and EC providers, with 34 KOLs and 155 providers interviewed. Targeted KOLs included public authorities, parliament members, professional association members, development partners, NGO representatives, religious leaders, pharmaceutical distributors, leaders of community-based organizations, and private practitioners. Providers included a wide range of cadres and included those currently providing, or have provided, EC, both in the public and private sectors, including doctors, midwives, nurses/ nurse assistants, pharmacists, and pharmacy counter staff, working in a number of settings: public facilities, private clinics, NGO facilities, pharmacies, adolescent counseling centers, and school infirmaries. 


\section{Primary Results}

\section{Provider survey}

A considerable proportion of providers (38\%) have not received any EC training. Among those trained, about half were trained as part of on-the-job training. Nearly a third of providers were never trained in FP counseling, and nearly four out of 10 providers have never received specific training on EC provision. Staff in private pharmacies, especially counter staff, tends to be less trained.

Providers have some ECP knowledge, but it can be strengthened. For example, improvements in knowledge about ECP's mode of action, its timing of use, and eligibility criteria can be strengthened. Although many providers think ECP is a safe product, negative views persist.

- While 72 percent of providers indicate ECPs can be provided to all women, irrespective of age or marital status, when questioned in-depth, responses are lower. Less than half of providers $(43 \%)$ responded that all married women could receive ECPs, and the proportion drops for youth and adolescent girls (37\%) ;

- Forty-one percent of trained providers were comfortable with ECPs sold without prescription, while the majority preferred tighter controls;

- Most providers preferred EC provision limited to conventional health facilities such as hospitals, health centers, private clinics, and pharmacies: They do not favor extending EC at community and school levels through other supply means ;

- Opinions are mixed on EC use by married women, unmarried adolescents, and sex workers.

Analysis of providers' ECP perceptions indicates:

- Providers believe primary users of EC are aged 15 to 29 years, particularly between 20 and 29 ;

- Providers do not favor regular EC use ;

- Providers feel EC users, more than others, are at greater risk of acquiring STIs, have multiple sexual partners, and not use regular contraception;

- Over two-thirds of providers indicated providing instructions on ECP use, and nearly twofifths reported answering client questions, but fewer providers referred clients to regular FP services $(28 \%)$ or provided information that ECPs do not protect against HIV and STIs ;

- $\quad$ Norlevo ${ }^{\circledR}$ is the commonly prescribed ECP.

\section{Key opinion leader survey}

Product beliefs:

- Apart from KOLs directly involved in the managing the reproductive health program, others, such as parliamentarians and other community leaders, are not as knowledgeable about EC. Different brands of EC products are not known to KOLs, who stressed the need for informing communities about this product.

- Few KOLs are informed about ECP's mode of action ;

- Many KOLs indicated that EC is legal, available in the national program, and sold in private pharmacies ;

- Some KOLs cited low availability of EC products, particularly in public health facilities, which have experienced stock shortages since 2010 due to the expiration of the public sector ECP product, Pregnon ${ }^{\circledR}$;

- The vast majority of KOLs have also raised EC's high cost in private pharmacies, which remain first sources of supply for EC users ;

- Legislation should be revised similarly to other contraceptive products: EC products are among Table A products, therefore requiring a prescription from a doctor or a midwife ;

- Although KOLs do not have specific information on EC guidelines and protocols, most are in favor of integrating EC in the national guidelines for FP service provision;

- Few KOLs are aware of EC studies in Senegal and their findings. 
Attitudes, opinions and perceptions relating to EC use:

- Most KOLs think ECPs are useful, especially among young people, because they help prevent unwanted pregnancies after unprotected sex, also in cases of rapes and incest, as they can avoid health and social consequences such as induced abortion and infanticide ;

- KOLs indicated perceived reluctance among providers about offering EC services. A public official stated, "Among providers, there are still some stereotypes. They have not quite accepted this method. They are concerned about potential overuse. Providers are directing users towards other methods such as injections and implants ;"

- KOLs do not share uniform views of preferred users of EC. For some KOLs, "EC should be limited to certain women: those with high-riske pregnancies, women victims of rape and sexual assault, sex workers and women having casual sex (e.g. migrants' wives, teenagers)". Others indicated "EC should be available to all women who need it and as long as there is no medical contra-indication for the method;"

- KOLs urged caution in expanding EC access to the community level. A Ministry of Health official said, "For extension to the bealth posts, there are no problems. But for health buts (i.e. facilities lower than bealth posts), I suggest we wait for the results of the initial experience to be well established, because even health workers at this level may overuse it ;"

- KOLs believe repeat use of EC is a reality, seen especially in pharmacies. They also believe, however, that repeat use can also increase risk of STI exposure and substitute for regular contraception.

\section{Recommendations}

This study's primary recommendations include:

- Informing communities for wider product knowledge ;

- Training providers ;

- Establishing a logistics management system ensuring product availability ;

- Improving product affordability ;

- Developing effective partnerships, especially with pharmacists ;

- Increasing advocacy with decision makers. 


\section{Introduction}

More commonly known as the "morning after pill," the Emergency Contraceptive Pill (EC) has been used for over 30 years throughout the world as a method for preventing unwanted pregnancy. EC is a unique contraceptive that prevents unwanted pregnancy after unprotected or poorly protected sexual intercourse. It is the only contraceptive method available that can be used immediately after unprotected sexual intercourse has occurred. Because it is very different from a scope of contraceptive methods, and because it efficiently prevents pregnancies for those families that use it, access to EC is an important part of overall family planning (FP) strategies, especially in contexts where the magnitude of unwanted pregnancies, violence, sexual abuse, and their consequences (e.g. unsafe abortions and infanticide) is high. The issue demands not only the attention but also the responsibility of public authorities and stakeholders.

Unfortunately, there is widespread ignorance in regards to this product, especially about its mechanism of action and the effect EC has on procreation. High priority must be given, on the level of reproductive health programs in general and of Family Planning (FP) programs in particular, to the diffusion of accurate information on EC.

In Senegal, initiatives for promoting EC are recent. The first initiative was sponsored by Equilibres et Population ${ }^{1}$, a partner of the ECafrique network ${ }^{2}$, through a pilot introduction of EC in ASBEF facilities from 2003-2005. Financed by the Compton Foundation ${ }^{3}$, this project was conducted in partnership with HRA PHARMA ${ }^{4}$. The goal was to introduce EC as a way to prevent unwanted pregnancies and unsafe abortions, and especially as a way to gear women towards regular contraceptive use. Activities focused on advocacy, the IEC, training providers, and the provision of EC services. This pilot project demonstrated that the usefulness of EC was well received by the public and that providers, once trained, found the product easy to administer. In 2005, ECafrique, in collaboration with Equilibres et Population, launched a sub-regional initiative on EC to strengthen lessons learned from the pilot intervention. This sub-regional initiative has engaged the Senegalese Ministry of Health and Prevention in implementing training activities and IEC advocacy in favor of EC. With support from Population Council, several studies have been conducted. The first study, "EC: A Glance at the Issue in Senegal" (2005), demonstrated the lack of public knowledge about EC. The second study, done in 2006, was diagnostic. It showed the need to reinforce information on EC to providers and the community. In 2006, the strategic evaluation of the national FP program revealed that providers as well as clients had limited knowledge of EC. This assessment also showed that the provision of EC services was limited to a few health centers and that the large majority of providers had no specific EC training. These conclusions were corroborated by the Study of Situational Analysis (AS) of the reproductive health services that was conducted in 2007, which showed that only $10 \%$ of Service Delivery Points (SDP) had dedicated EC products and that $37 \%$ of providers interviewed were not trained in EC.

In 2008, in collaboration with the CEFOREP, a study on unwanted pregnancy prevention in schools in the area of Pikine-Guédiawaye identified providers' training, youth awareness, and improvement of the availability and access to EC products as key actions to be undertaken in the context of EC promotion.

The conclusions of these studies contributed to the integration of EC in policies and reproductive health service norms. Already in 1998, EC was introduced into the curriculum for provider training. In 2000, EC was mentioned for the first time in the Policies, Norms, and Protocols (PNP). These PNP mentioned that Combined Oral Contraceptives, progestin pills, and IUDs could be used as part of EC. In 2005, Pregnon was introduced as the first dedicated EC method in the PNP.

Between 2006-2010, through Population Council's support, the Ministry of Health was able to train almost 1,200 providers, pharmacists and pharmacists' assistants, and health agents on EC provision and on how to educate clients about the use of this product. Teaching materials were developed and distributed to providers and health workers in several regions. With the support of UNFPA, the introduction of Pregnon in public sector SDPs enhanced accessibility to EC in the national health system. In the private sector, PRODIPHARMA has provided the distribution of Norlevo since 2005.

1 Equilibres et Population is an NGO based in Paris that was founded in 1993 by doctors and journalists to promote the proper use of public aid for development.

2 The African Forum on Emergency Contraception or ECafrique is a network of professionals involved in the field of bealth that aims to increase the availability of quality EC services in Africa. This network was created in 2002 and is sponsored by Population Council, an American NGO based in New York.

3 The Compton Foundation is a nonprofit organization based in California, USA, which aims to ensure buman and environmental security and preserves the rights of future generations. 4 HR A PHARMA is an institution whose objective is to develop and commercialize medicine or medical devices that meet real needs in bealth without raising the interests of pharmaceutical companies. It developed Norlevo, which is an EC product. 
In 2009, the study conducted in private pharmacies revealed that they were still the main source of EC provision and highlighted the need to harmonize EC provision procedure in the private sector. This study also showed the need to keep pharmacists and their assistants up to date on new EC provision protocols.

In 2010, the Reproductive Health Division, with support from Population Council, performed an assessment of the EC integration process into the national health system through a national forum on EC. This forum revealed that there was a real promotional problem regarding EC in the national health system despite the efforts made.

Indeed, the following was noted:

- A widespread lack of public awareness about the product;

- Persistent rumors about EC due to the specificity and sensitive nature of the product;

- Low inclusion of EC in routine service delivery, especially during initial counseling and FP/ IEC awareness campaigns;

- Although private pharmacies are the main supply source for EC users, service providers at pharmacies need to be updated as to new EC provision protocols.

EC use in the public system remains very low if one refers to routine statistics $(<2 \%)$. In the private sector, because of the lack of a functioning information system, the actual use of $\mathrm{EC}$ in pharmacies is not known.

EC service delivery in the public sector continues to be hampered by insufficient promotion of the product. The beliefs, attitudes, and practices of the general population, and of providers in particular, will impede the promotion and use of this product with the groups who need it the most.

Thus, in the context of repositioning EC in FP programs, Population Council has conducted a study of the attitudes, beliefs, and practices of Key Opinion Leaders (KOLs) and providers around EC in collaboration with the Division of Reproductive Health (DRH).

This study is part of a multi-country study that also includes Nigeria and India. These three countries receive funding from the Bill \& Melinda Gates Foundation in support of the implementation of Urban Health Initiative underway in these countries.

\section{Goal of the Study}

The goal of this study is to propose innovative strategies to reposition EC in the public and private health sectors.

\section{Study Objectives}

\section{Main objective}

The study's overall objective is to collect information from opinion leaders and providers about their EC knowledge, attitudes, and practices and to understand the options and perceptions that may influence EC policy and programs.

\section{Specific objectives}

- To document providers' EC attitudes, beliefs and practices, including the issue of repeated use;

- To capture KOLs' views and perceptions about EC policy and program issues;

- To collect suggestions and recommendations for establishing appropriate interventions for the repositioning of EC in public and private health sectors.

\section{Methodology}

\section{Study sites}

- The study was conducted in August and September 2011 in urban areas in Dakar and Thiès targeted by the "Urban Reproductive Health Initiative in Senegal" (ISSU) project, funded by the Bill \& Melinda Gates Foundation. The choice of sites provides a good opportunity to collaborate with ISSU. 
The choice of the cities of Dakar, Thiès, and Mbour is justified by:

- Dakar: the choice of Dakar is justified because it is the largest population center in the country and because it represents many of the social and economic problems of the country in general.

- Thiès: Thiès was chosen because it is the second urban center at the national level and because it is important to have an EC supply available outside of Dakar. Thiès also houses a regional hospital and several private clinics.

- Mbour: Mbour was included as an emerging urban center with an economic and social profile that differs from the two other choices. Mbour is characterized by its touristic profile, which exposes adolescents and youth to crucial problems linked to premature sexuality and its consequences (e.g. unwanted pregnancies).

\section{Study target}

The study targeted two types of respondents:

- Key Opinion Leaders (KOL) : this target includes public authorities (officials from the Ministries of Health, National Education, Youth, and Gender, etc.), members of parliament, members of professional associations (Order of Pharmacists, Order of Doctors, midwives and women lawyers associations), representatives of development partners, local NGO members, professional and religious networks (Journalists and Islamic networks, Siggil Jiggen network), pharmaceutical distributors, and members of community-based organizations (CBO), especially women's, youth, and private sector practitioner associations. The choice of KOLs is justified by the fact that they play a major role in defining national policies and strategies and in resource allotment; the population listens to them and they can influence opinions. Their decisions matter so it is important to understand better their opinions and suggestions in order to build solid advocacy for EC repositioning.

- Service providers: the provider survey targeted a wide range of providers involved in FP service provision in the public, private, and semi-public sectors. These include doctors, midwives, nurses/nurses assistants, pharmacists and counter staff, providers involved in adolescent counseling centers, private clinics and NGO clinics, and school infirmaries.

\section{Selection of sample population}

Key opinion leaders: the selection of KOLs was made after systematic decision-making; KOLs were chosen based on the interest and involvement of their institutions with regards to EC and on the role and influence that these institutions could have on EC repositioning.

Providers: at the first level, the selection was made based on Service Delivery Points (SDP) that usually provide FP services, including EC. The choice of SDPs took into account the representation of types of SDPs (public/private/semi-public) and the level of attendance of the SDP by the population. These SDPs included public sector facilities (hospitals, health centers, and health posts), semi-public facilities (COUD Social Center, Dakar Dem Dikk, Social Security Office), private clinics and pharmacies, NGO clinics (ASBEF, ACDEV), and adolescent counseling centers. At the second level, providers who have, in the past, offered an EC method and those who continue to do so were included in the study and interviewed after having giving their consent. At least one provider per SDP was interviewed.

\section{Data collection tools and issues explored}

Key opinion leaders: a semi-structured interview guide was administered to each KOL. The issues explored focused on product knowledge (its legal status, its mechanism of action, its efficacy, and its timing of use); EC service delivery; EC policies, norms, and protocols; EC research; EC perceptions, attitudes, and practices; barriers linked to delivery and access; EC use; and suggestions for EC promotion. Interviews were conducted by the study coordinator with support from a sociologist.

Providers: an individual quantitative questionnaire was administered to providers. As with interviews with the KOLs, questions focused on product knowledge; EC perceptions, attitudes, and practices; EC use; and their experience with EC provision. Interviews were conducted by DHR coordinators who were previously trained in questionnaire administration. 


\section{Ethical considerations}

For both KOLs and service providers, an informed consent form was given before the beginning of the interview. Participation in the survey was voluntary and no compensation was given to participants. Interviews respected the privacy and the anonymity of the interviewees throughout the survey and data processing through the use of codes for all personal information related to participants. No name was recorded.

\section{Data management and analysis}

The provider survey: data entry was done with Epidata software; the data was transferred to SPSS for analysis. Univariant and bivariant analyses were performed.

The KOL survey: content analysis was used for qualitative information processing gathered from the KOLs. This analysis was done along similar themes to allow for comparison between the three countries covered by the study.

\section{Assessment of Data Collection}

\section{Key Opinion Leaders (KOL)}

Table 1 shows KOL distribution by profile. A total of 34 KOLs were interviewed, of which 11 are involved in public institutions (officials from the Ministries of Health, Education, Justice, Youth, members of parliament, etc.), five are members of professional and religious associations (Women lawyers and Islamic associations, etc.), four are representatives of development partners, and the rest are representatives of institutions involved in EC distribution (National Supply Pharmacy, head of logistics at the DRH, PRODIPHARM), members of Community based organizations (CBO) (such as Synergie Banlieue and Youth Action Movement), and private practitioners. The wide choice of different targeted institutions in this study responded to the need for a diversified picture of officials' opinions (public policy, civil society, community and NGO decision makers). These officials are likely play a role in determining policy and program choices for EC repositioning.

Table 1: Distribution of KOL by profile

\begin{tabular}{lc}
\hline KOL profile & Number \\
\hline Policy and program decision makers & 11 \\
\hline Professional association members & 5 \\
\hline NGO members & 3 \\
\hline Development partners & 4 \\
\hline Practitioners & 1 \\
\hline Distributors & 3 \\
\hline Community based organization members & 7 \\
\hline Total & 34 \\
\hline Source: : KOL survey, Juby 2011 &
\end{tabular}

\section{Providers}

The provider survey covered a wide range of SDPs including public, private, and semi-public health sanitary facilities. 109 SDPs were visited, of which 36 were pharmacies, 26 were health posts, 13 were private clinics, and 15 were health centers. The sampling also included specific facilities such as counseling centers for adolescents (4) and school infirmaries, which are specifically designed for adolescents/youth in school settings (2). Most of the SDPs are concentrated in Dakar (82\% of SDPs).

Table 2: Distribution of Service Delivery Points by type

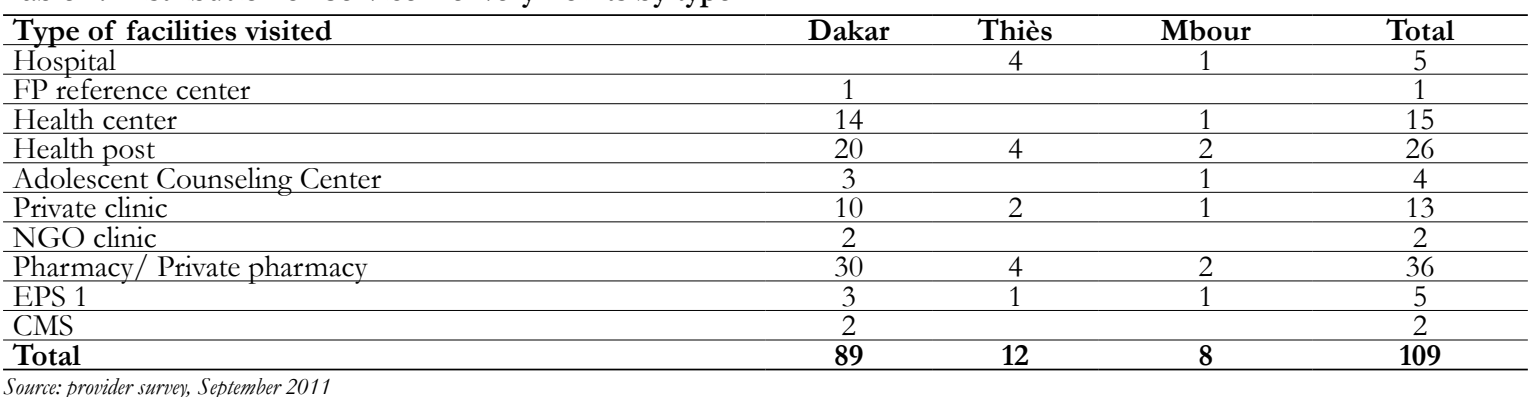

Source: provider survey, September 2011

At the 109 SDPs visited, 155 providers were interviewed. Midwives represented the majority of the sampling (54\%); the strong presence of midwives in the sampling is explained by the fact that they are the first line providers in FP service delivery. Counter staff in pharmacies made up 19\% followed by 
pharmacists $(17 \%)$ and doctors $(6 \%)$. The other categories had little representation in the sampling.

Table 3: Distribution of providers by professional category

\begin{tabular}{lcccc}
\hline Type of provider & Dakar & Thiès & Mbour & Total \\
\hline Midwife & 68 & 10 & 5 & $\mathbf{8 3}$ \\
\hline Pharmacist & 21 & 3 & 2 & $\mathbf{2 6}$ \\
\hline Doctor & 8 & 1 & 1 & $\mathbf{1 0}$ \\
\hline Counter staff & 28 & 2 & & 30 \\
\hline Other & 4 & & 2 & $\mathbf{6}$ \\
\hline Total & $\mathbf{1 2 9}$ & $\mathbf{1 6}$ & $\mathbf{1 0}$ & $\mathbf{1 5 5}$ \\
\hline Source: provder survey, September 2011 & & & &
\end{tabular}

Women made up a majority of the provider sampling (71.6\%). In Mbour, the number of men was higher (40\%) compared to Thiès and Dakar (27.9\% and 25\% respectively).

Table 4: Distribution of providers by gender

\begin{tabular}{lcccccccc}
\hline \multirow{2}{*}{ Gender } & \multicolumn{2}{c}{ Dakar } & \multicolumn{2}{c}{ Thiès } & \multicolumn{2}{c}{ Mbour } & \multicolumn{2}{c}{ Total } \\
\cline { 2 - 9 } & $\mathbf{N}$ & $\mathbf{0}$ & $\mathbf{N}$ & $\mathbf{0}$ & $\mathbf{N}$ & $\mathbf{\%}$ & $\mathbf{N}$ & $\mathbf{0}$ \\
\hline Male & 36 & 27.9 & 4 & 25 & 4 & 40 & 44 \\
\hline Female & 93 & 72.1 & 12 & 75 & 6 & 60 & 111 \\
\hline Total & $\mathbf{1 2 9}$ & $\mathbf{1 0 0}$ & $\mathbf{1 6}$ & $\mathbf{1 0 0}$ & $\mathbf{1 0}$ & $\mathbf{1 0 0}$ & $\mathbf{1 5 5}$ \\
Source: provider survey, September 2011 & & & & & & & & $\mathbf{1 0 0}$ \\
\hline
\end{tabular}

The average age of providers was 43.5 years with a minimum age of 25 and a maximum of 70 . The average months of EC experience was 59.4 months, or almost 5 years, which corresponds to the introduction of training activities for providers within the national FP program that began in 2005. However, Table 5 indicates that certain providers have experience (22 years) previous to the initiative to introduce EC into the national health system, which dates to 10 years ago with the introduction of Pregnon and Norlevo in the public and private sectors. These providers were most likely using traditional contraceptive pills and perhaps IUDs, which were methods previously used for FP.

Table 5: Distribution of providers by age and EC experience

\begin{tabular}{lcccc}
\hline & Dakar & Thiès & Mbour & Total \\
\hline Provider age (years) & & & & 10 \\
\hline $\mathrm{N}$ & 129 & 16 & 45 & 44 \\
\hline Average & 44 & 43 & 44 & 25 \\
\hline Minimum & 25 & 29 & 31 & 70 \\
\hline Maximum & 70 & 59 & 56 & 136 \\
\hline Number of months of EC experience & & & & \\
\hline Average & 111 & 15 & 10 & 0 \\
\hline Minimum & 58 & 45 & 102 & 0 \\
\hline Maximum & 0 & 1 & 36 & 264 \\
\hline
\end{tabular}

Table 6 shows the quasi-effectiveness of EC provision. Amongst the 155 providers who have provided EC in the past, $92 \%$ continue to do so. However, 11 out of 83 midwives who have provided EC in the past no longer do.

Table 6: Percentage of providers currently offering EC by professional category and region

\begin{tabular}{|c|c|c|c|c|c|c|c|c|}
\hline \multirow{2}{*}{ Professional category } & \multicolumn{2}{|c|}{ Dakar } & \multicolumn{2}{|c|}{ Thiès } & \multicolumn{2}{|c|}{ Mbour } & \multicolumn{2}{|c|}{ Total } \\
\hline & $\mathbf{N}$ & $\%$ & $\mathbf{N}$ & $\%$ & $\mathbf{N}$ & $\%$ & $\mathbf{N}$ & $\%$ \\
\hline Pharmacist & 21 & 100 & 3 & 100 & 2 & 100 & 26 & 100 \\
\hline Counter staff & 27 & 96.4 & 2 & 100 & & & 29 & 96.7 \\
\hline Other & 4 & 100 & & & 2 & 100 & 6 & 100 \\
\hline Total & $\begin{array}{c}4 \\
118\end{array}$ & 91.5 & 15 & 93.8 & 10 & 100 & 143 & 92.3 \\
\hline
\end{tabular}

\section{Key Opinion Leaders (KOL): Who are they?}

The choice of KOLs was motivated by the major role that they play in the influencing the ideas and opinions of community and especially for their role in decision-making at the social, political, and economic levels. Indeed, KOLs play a key role in the definition of policies and national strategies. They fix national priorities, especially the allotment of resources. Their decisions matter so it is important to understand better their opinions and perceptions on major social interest topics such as family planning and emergency contraception.

The involvement of KOLs in EC repositioning strategies is justified by the fact that they are potential key supporters or critics of EC. KOL integration in programs remains a fundamental issue for EC advocacy. In the context of this study, a wide range of KOLs was targeted from policy makers/program managers, members of professional associations/networks, members of local NGOs, development partners, CBO representatives, distributors, and private practitioners. 
Table 7: List of visited institutions

\begin{tabular}{|c|c|}
\hline INSTITUTIONS & INSTITUTIONS \\
\hline $\begin{array}{l}\text { Public policy makers: } \\
\text { - Ministry of Health and Prevention (DRH) } \\
\text { - Ministry of National Education } \\
\text { - Ministry of Youth } \\
\text { - } \quad \text { National Assembly } \\
\end{array}$ & $\begin{array}{l}\text { Local NGOs: } \\
\text { • ASBEF } \\
\text { • Action for Development (ACDEV) }\end{array}$ \\
\hline $\begin{aligned} & \text { Development partners: } \\
& \text { • } \text { WHO } \\
& \text { • } \text { UNFPA } \\
& \text { • } \text { USAID } \\
& \text { - } \text { Marie Stopes International (MSI) } \\
&\end{aligned}$ & $\begin{array}{l}\text { Practitioners: } \\
\qquad \quad \text { A private doctor }\end{array}$ \\
\hline $\begin{array}{l}\text { Professional associations: } \\
\text { - Order of Senegalese doctors } \\
\text { - Order of Senegalese pharmacists } \\
\text { - National Association of Senegalese Midwives }\end{array}$ & $\begin{array}{cl}\text { CBOs: } & \\
\text { - } & \text { Siggil Jiggen network } \\
\text { - } & \text { Forum for African Women Educationalist } \\
\text { - } & \text { Movement for Youth Action } \\
\text { - } & \text { Synergie Banlieue } \\
\end{array}$ \\
\hline \multirow[t]{2}{*}{$\begin{array}{l}\text { Networks: } \\
\text { • Islamic and Population networks (Religious) } \\
\text { • Health journalists and Population networks }\end{array}$} & $\begin{array}{ll}\text { Distributors: } \\
\text { • } & \text { PRODIPHARM } \\
& \text { National Supply Pharmacy } \\
& \text { - ADEMAS }\end{array}$ \\
\hline & $\begin{array}{c}\text { Police: } \\
\text { • The Camp Pénal Women's Prison }\end{array}$ \\
\hline
\end{tabular}

\section{Product Knowledge}

\section{General Product Information}

Besides the KOLs who are directly involved in the management of routine reproductive health programs (especially leaders in the Ministry of Health, Ministry of National Education, development partners, and local NGO members), the majority of KOLs do not possess accurate information on EC. They know it by the name of "the morning after pill," but they cannot name different EC brands available in the country, nor can they discuss its mechanism of action or its side effects. This is the case with members of parliament, journalists, religious leaders, and certain members of CBOs. Thus it is important to increase EC knowledge amongst these KOLs by giving them more specific product information. Furthermore, it is important to raise awareness about product safety. This could also push leaders to adhere to policies that promote EC.

\section{The best-known EC products}

According to KOLs, the main EC products available are the following:

- Norlevo ${ }^{\circledR}(1.5 \mathrm{mg})$, which was made available by the DRH before 2006 , but it is currently only available in private pharmacies;

- $\operatorname{Pregnon}^{\circledR}$, which was introduced in the public system by the national FP program since May 2006 thanks to a UNFPA donation. However, the available stock expired in September 2010 due to lack of promotion and distribution by public sector providers;

- DUET, which is the new product that will replace Pregnon ${ }^{\circledR}$;

- Optinor, which is only available in ASBEF facilities;

- Conventional contraceptives pills (Loféménal, Microval, ovrette, etc.);

- IUDs.

\section{EC legal status}

The vast majority of KOLs believe that EC products are legal based on the fact they are available in the FP national program alongside other contraceptive products and are sold in private pharmacies. Speaking of Norlevo ${ }^{\circledR}$, a member of a professional association stated: "It is a licensed product. [...] As for otherproducts found in private pharmacies, it received the visa from Pharmacy and Laboratory Administration" (a member of a professional association). However, according to some KOLs, although EC products are licensed, the pharmaceutical regulation of contraceptives in general and EC in particular should be reviewed. One member of a professional association stated: "Norlevo ${ }^{\circledR}$ figures on the list of Table A drugs and should be sold 
upon presentation of a prescription, but in reality, it is given upon demand" (a member of a distributors network). According to these KOLs, this situation should be fixed because now, because "according to regulations, only doctors and midwives are allowed to prescribe this method; however, in practice, it has been noted that nurses provide this product. [...] It is important therefore to eliminate some of these contradictions" (a distributor).

\section{Product usefulness}

All KOLs are unanimous on the usefulness of the product and believe that the product should be popularized for several reasons:

- "So that everyone will have the information";

- "It is an efficient product to prevent unwanted pregnancies as well as cases of death and some social situations (e.g. infanticide, abandonment, clandestine abortions and their social consequences)";

- "It is a useful product that has its place in the system to respond to unmeet needs";

- "It can belp young people better manage their futures";

- "It is easy to use";

- "For different reasons, there are women who do not use a regular method of contraception".

Some KOLs justify the usefulness of the product based on the fact that "it can belp fight girls' bigh dropout rate from school and it can help certain organizations fight against sexual violence by taking better care of victims of abuse or sexual violence" (a member of a professional organization).

Although for the popularization of this product, some KOLs reveal their fears and believe that its use should be supervised because "it should not be used as the one and only method" (a decision maker).

Some reservations on the part of KOLs are for personal reasons: "Personally, as a Muslim, mother, and educator, I think that its use should be limited. Sociocultural values cannot be violated in one fell swoop. With this method, we must be careful not to offend people. Because of the sensitivity of this subject, religious leaders should be involved. But in critical situations (e.g. rape and incest), it should be used to belp young people, at least on a psychological level' (a decision maker).

\section{Product efficacy and safety}

According to KOLs, EC is considered effective and safe if it is properly taken at the right time as well as properly conserved. In principle, all providers understand EC insofar as they have been trained. KOLs justify product efficacy by high demand in private pharmacies and because few failures and complaints have been reported. Only one member of a CBO mentioned a failure. As for the side effects, the KOLs do not exclude them, but they are minor. According to some KOLs, "This product is safe due to the fact that before its introduction, as for any drug, it received approval from the DPL" (member of a professional association).

The KOLs do not exclude the probability of the existence of counterfeit products in the context of the market, especially in the informal sector, which is very porous because it lacks an efficient monitoring system. According to KOLs, "As with all drugs, EC products can be objects of counterfeit" (a decision maker). No KOL reported having seen or heard of the existence of counterfeit products. These KOLs depend on monitoring results: "All contraceptive products were enrolled in the quality control program and no counterfeit product was reported" (a program manager).

\section{EC in Policies/Norms and national guidelines}

EC has been incorporated in the latest Policies/Norms and Protocol (PNP) documents under Family Planning/Reproductive Health reviewed in 2007-2008. It also appears prominently in the new version of PNP that became available in 2012. It must be noted that a majority of KOLs are in favor of EC integration into the national guidelines as long as "EC is part of a range of contraceptive products available in the national FP program" (a program manager/decision maker). However, KOLs are not very aware of these national guidelines.

\section{Supply source/logistics system}

Senegal's EC products are supplied through two systems. In the public sector, supply follows the official system of contraceptive products and is done with the DRH with support from development partners, mainly UNFPA, which has supported the DRH in the establishment of these products (Pregnon ${ }^{\circledR}$ ) since 2006. In the first stage, the DRH directly dispatches the products to the medical regions. Districts, 
where activities are implemented operationally, get their supply from their medical regions. Since 2010, through an agreement signed between the DRH and the Central Medical Stores (CMS), the latter does DRH's purchasing and ensures supply and distribution according to the division's recommendations, including donated products. A rates system for contraceptive products including EC was validated by the Ministry of Health, who fixed and published the official prices for contraceptive products at all levels of the health system. The lack of contraceptive consumer data through the Quarterly Stock Registers (RTS) is a weak link in the supply system, as real consumption is not known, which in turn limits the quality of product orders. Since 2010, the system has witnessed product shortage due to the expiration of Pregnon ${ }^{6 \circledast}$ because of a lack of promotion on the part of providers. Currently, a new product named DUET has replaced Pregnon ${ }^{\circledR}$ in the public system. DUET was commissioned by the CMS in the context of the agreement, but the quantities available did not cover the country's annual needs. Qualified personnel at all public facilities, except at health huts, ensure EC provisions. Generally, gynecologists and midwives provide the product.

In the private sector, $\mathrm{EC}$ is sold in private pharmacies under the brand name Norlevo $^{\circledR}$. In private clinics, doctors and midwives generally provide EC through a prescription that the client can then fill at a private pharmacy. Norlevo ${ }^{\circledR}$ is sold to customers at 3,275 FCFA. Five main wholesalers share this private market: PRODIPHARM, LABOREX, SODIPHARM, COPHASE, and BIOPHRAM. According to estimates, "almost 80,000 units of Norlevo $0^{\circledR}$ are consumed in private pharmacies. [...] The Dakar region represents almost 60\% of the national market. [...] The product is especially used in cities" (a distributor).

At ASBEF, "Optinor is available thanks to support from the IPPF. It is sold at 2,000 FCFA" (an NGO employee).

\section{EC research}

Few KOLs were informed about the existence of EC studies done in Senegal and their conclusions. The principal studies that were cited by KOLs were:

- "EC: A Glance at the Issue in Senegal" (Population Council 2005);

- "Diagnostic Study on EC" (CEFOREP/2006);

- "Study on the Prevention of Unwanted Pregnancies in Schools in the Pikine-Guédiawaye Region" (Population Council et CEFOREP 2007);

- "Study on EC in Private Pharmacies" (Population Council 2009).

Some KOLs expressed interest in certain research concerns:

- EC acceptability by the population and by decision makers;

- Stigmatization of EC users;

- Religious aspects linked to EC use;

- Efficacy and safety of the product;

- Perception of parents and of the community of EC use by adolescents/unmarried youth;

- Effects of repeated use/abuse;

- EC use and exposure to HIV/AIDS;

- KAP survey among youth;

- KAP survey among providers.

\section{KOL EC Attitudes, Opinions, and Perceptions}

\section{Product acceptability}

Overall, KOLs have a high opinion of EC. They think that it has a place in the range of contraceptives and may provide a remedy in certain circumstances (e.g. forgotten pill, rape, incest, etc.). According to some, "It should be promoted even amongst young single people because it prevents unvanted pregnancies (especially in the case of neglecting to take the pill, rape, and incest) and their social consequences (e.g. induced abortion, infanticide)" (***author).

This is confirmed by the comments of some KOLs:

6 Almost 25,000 units of Pregnon expired due to failure of providers to deliver the product. This shortage reflects the dysfunctional supply and management system of contraception products noted in 2011 
"This is a method that we need in the context of our activities because unwanted pregnancies can have very serious social consequences (for example, women imprisoned for infanticide)" (member of a professional association).

"For young people who are not married, I am not against it. The evidence shows that today sexual intercourse is trivialized even though we are in a Muslim country. It would be hypocritical to remain silent. [...] I would prefer that they use EC than commit infanticide" (NGO member).

\section{EC can contribute to FP repositioning}

"We are in advocacy. We must help people correct certain errors. Thus, it must be known and accepted by the whole population, and not be limited to only one target (youth)" (program manager).

However, some believe that distribution should be accompanied with advice for the following reasons:

- Better targeting of men since EC is a product destined specifically for women but is not known to men who might need to buy it for their partners. Indeed, one distributor stated that "70 to $80 \%$ of those who buy it are men. It is a product destined for women but bought by men. They are relatively young and they know the price" (distributor).

- Inform EC users that this is an exceptional method that cannot replace regular contraception because "young people seem to use it as regular contraception" (program manager).

- Inform young people that EC does not protect against STIs because "EC users are more prone to sexual libertinism and to not protecting themselves against STIs and HIV" (NGO member).

The KOLs put forward some reservations about EC use, especially promiscuity, abuse, replacement of regular FP methods, religious considerations, and lack of protection against STIs/HIV/AIDS.

According to one KOL: "It should be popularized, but we should first promote condoms to protect against STIs/ HIV. It is a back up method that does not protect against AIDS" (members of professional associations).

\section{Perceptions of provider attitudes toward the product and its acceptability}

According to some KOLs, providers still feel some reluctance despite training. This would often be linked to personal issues.

"There are some limitations with providers. Midwives are a bit blocked; they make the connection with abortion. Perhaps there is also a link with the target (young people)" (development partner).

"With providers of a certain age bracket, there could also be a problem because they envision their daughters in front of them. Their reactions sometimes go beyond the work setting" (NGO representative).

"For providers, there are still some stereotypes. They have not yet fully accepted this method. [...] They are concerned with overuse. And we find that counseling is now very biased towards injections and implants" (public authority).

\section{EC provision}

The opinions of KOLs remain divided as to who should receive EC:

For some: "EC must be limited to certain categories of women: those with an at risk pregnancy, victims of rape or sexual assault, prostitutes, and woman who have occasional sex (e.g. wives of emigrants, adolescents)" (member of a CBO).

For others: "EC must be available for all women who need it as long as there is no medical contraindication for the method" (decision maker).

It is the same in regards to where EC should be made available: some believe that EC services should be expanded to other types of less conventional sanitary facilities such as sanitary facilities in military camps, Counseling Centers for Adolescents (CCA), Medical Infirmaries for Schools (IME), and universities. Others do not think that EC should be available at the community level: "There is no problem in health posts. As for the buts, I suggest waiting until the initial experience is firmly established and even health workers at this level may overuse it' (program manager).

\section{Repeated EC use}

The vast majority of KOLs believe that contraceptive use should be exceptional; they define repeated use as exceeding once a year. The vast majority of KOLs argue that repeated use is a reality that is mostly seen in private pharmacies. According to pharmacists, repeated use is noted mainly with young people. However, the lack of reliable statistics does not allow them to confirm this. 
KOLs believe that repeated use can cause problems, especially:

- Abuse of product;

- Replacement or halt of regular contraception;

- Exposure to HIV.

\section{Barriers to EC Provision and Access}

\section{EC Access}

According to KOLs, the main barriers to EC access are the following:

- Lack of information;

- Provider's attitude (e.g. reception or bias);

- Product unavailability;

- Shame;

- Distance from supply source, mainly the SDP;

- High cost of EC products in pharmacies;

- Side effects linked to product use;

- Stigma especially in areas where social pressure is strong: "When someone asks for this product, you say to yourself that he has done something or has the intention of doing something" (decision maker);

- Religious convictions;

- Husband's lack of understanding;

- Rumors about contraception in general.

\section{Barriers to EC Provision}

According to KOLs, the main barriers to EC provision are the following:

- Provider's lack of training;

- Religious convictions;

- Product unavailability due to the expiration of the previous stock and the non-renewal of the stock at $\mathrm{SDP}^{7}$;

- The wait time is considered too long by client;

- Administrative paperwork faced by clients;

- Unsuitable operating hours;

- Lack of privacy and anonymity at visits (recording of personal information such as name or address) at public facilities;

- Lack of counseling at pharmacies where client-provider interaction is very low (no space for counseling).

According to KOLs, the main challenges to EC promotion are the following:

- Access to product information and communication;

- Product availability:

- Provider training, including pharmacists and counter staff;

- Geographic and financial accessibility;

- Support from the public and certain providers;

- Harmonization of practices on usage times because pharmacists rely on product inserts;

- Regulatory review (Table A drug); it would therefore be necessary to declassify this product to facilitate access;

- Quality of service (e.g. good counseling, privacy, anonymity, and lack of stigma).

7 The previous stock of Pregnon acquired through the DRH expired in September 2010, and it was only renewed recently. The amount available does not cover the regions' annual needs. The lack of availability of EC products is in a context of overall contraceptive product shortage due to the problem of retaining information, which occurs when the quarterly inventories required for planning future contraceptive needs are not transmitted 


\section{KOL Recommendations for EC Promotion}

According to KOLs, EC promotion should be a multisectoral approach that involves a variety of stakeholders, namely:

Public authorities (Ministry of Health, Ministry of National Education, Ministry of Justice, Ministry of the Family, Ministry of Youth, etc.):

- Community stakeholders (CBO, Peer Educators, Badienu Gox);

- Religious leaders;

- Parliamentarians;

- The media;

- Lawyers;

- Civil society;

- Traditional communicators.

KOLs have made the following recommendations for priority EC intervention:

- Strengthen information for a wider dissemination of the product;

- Train providers;

- Ensure proper logistical management to guarantee product availability;

- Increase financial accessibility;

- Develop partnerships through more involvement of pharmacists;

- Develop advocacy with decision makers;

- Develop research on product acceptability and safety.

\section{EC Training for Providers}

Counseling is an important component of service delivery that guarantees not only the client's informed choice but also, as a result, the quality of services offered. The graph below indicates that almost one third of providers have not had any training in FP counseling. The training deficit is particularly noticeable with providers in pharmacies: only $13 \%$ of counter staff and $42 \%$ of pharmacists have received training in FP counseling. The percentage is 94 amongst midwives. This is due to the fact that FP training programs have targeted public sector providers; the private sector benefited from few FP training programs. It is important to better target this sector in order to harmonize FP service delivery at a national level.

Graph 1: Proportion of providers previously trained in FP counseling by qualification

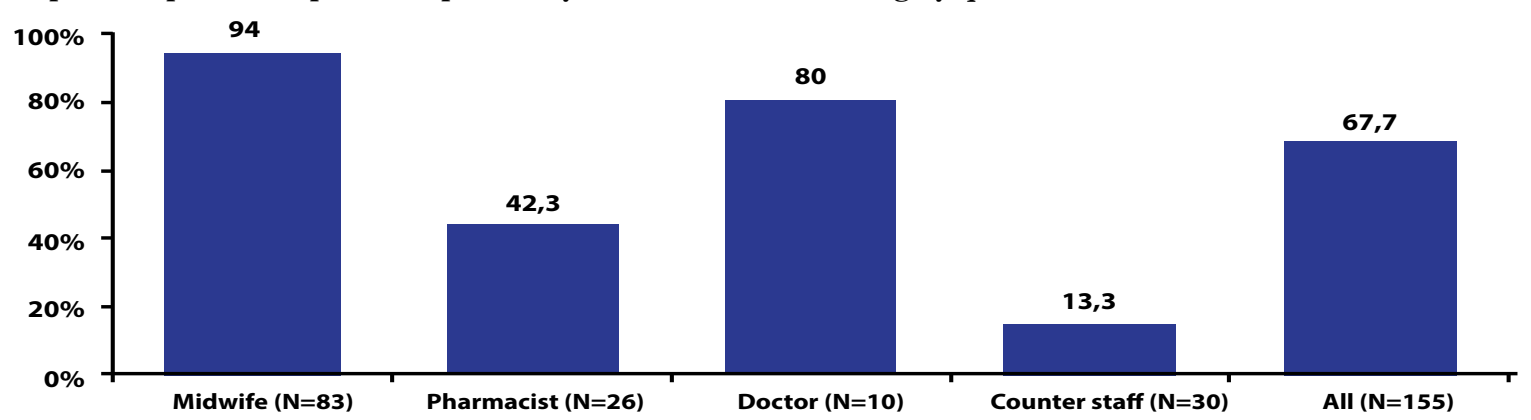

Table 8 shows that EC training is not very integrated in the initial training for providers. Only $22.6 \%$ of providers received EC training during their basic training. Indeed, EC integration in the provider-training curriculum is very recent. $51.6 \%$ of them received it while on the job. It can be noted that $38.1 \%$ of providers have never had any specific EC training, nearly four providers in ten. Dakar has the highest rate of providers who have never received specific EC training (39.5\%). 
Table 8: Percentage of providers with EC training

\begin{tabular}{|c|c|c|c|c|c|c|c|c|}
\hline \multirow[t]{2}{*}{ Training } & \multicolumn{2}{|c|}{$\begin{array}{c}\text { Dakar } \\
(\mathrm{N}=129)\end{array}$} & \multicolumn{2}{|c|}{$\begin{array}{l}\text { Thiès } \\
(\mathrm{N}=16)\end{array}$} & \multicolumn{2}{|c|}{$\begin{array}{l}\text { Mbour } \\
(\mathrm{N}=10)\end{array}$} & \multicolumn{2}{|c|}{$\begin{array}{c}\text { Ensemble } \\
(\mathbf{N}=155)\end{array}$} \\
\hline & & $\%$ & & $\%$ & & & & \\
\hline $\begin{array}{l}\text { Trained specifically in EC during basic training } \\
\text { Trained specifically in EC on the job }\end{array}$ & $\frac{20}{65}$ & $\frac{20.2}{50.4}$ & $\frac{4}{10}$ & $\frac{25}{625}$ & $\frac{5}{5}$ & $\frac{50}{50}$ & $\begin{array}{l}35 \\
80\end{array}$ & 22.6 \\
\hline Has not received specific training in EC & 51 & 39.5 & 3 & 18.8 & 2 & 20 & 56 & 36.1 \\
\hline Trained in EC during the last 12 months & 18 & 14 & 6 & 37.5 & 1 & 10 & 25 & 16.1 \\
\hline
\end{tabular}

Only 16.1\% received specific EC training in the 12 months preceding the survey.

Table 9: Percentage of providers with EC training by professional category

\begin{tabular}{|c|c|c|c|c|c|c|c|c|}
\hline \multirow{2}{*}{ Professional Category } & \multicolumn{2}{|c|}{ Dakar } & \multicolumn{2}{|c|}{ Thiès } & \multicolumn{2}{|c|}{ Mbour } & \multicolumn{2}{|c|}{ Total } \\
\hline & $\mathbf{N}$ & $\%$ & $\mathbf{N}$ & $\%$ & $\mathbf{N}$ & $\%$ & $\mathbf{N}$ & $0 \%$ \\
\hline Pharmacist & 12 & 57.1 & 3 & 100 & 2 & 100 & 17 & 65.4 \\
\hline Counter staff & 7 & 25 & 2 & 100 & & & 9 & 30 \\
\hline Other & 3 & 75 & & & 2 & 100 & 5 & 83.3 \\
\hline Total & 78 & 60.5 & 13 & 81.3 & 8 & 80 & 99 & 63.9 \\
\hline
\end{tabular}

$63.9 \%$ of providers who have already provided EC received specific EC training. The highest percentages of providers without EC training were found with counter staff $(70 \%)$ and pharmacists $(34.6 \%)$.

\section{EC Knowledge}

Table 10 shows that there is significant percentage of providers who do not understand EC mechanism of action: $57.4 \%$ quoted the stoppage of ovulation and $63.9 \%$ the prevention of egg implantation.

Table 10: Percentage of providers' understandings of the EC mechanism of action

\begin{tabular}{|c|c|c|c|c|c|c|}
\hline & \multicolumn{2}{|c|}{ Without Training } & \multicolumn{2}{|c|}{ With Training } & \multicolumn{2}{|c|}{ Total } \\
\hline & $\mathbf{N}$ & $\%$ & $\mathbf{N}$ & $\%$ & $\mathbf{N}$ & $\%$ \\
\hline Inhibits ovulation & 25 & 44.6 & 64 & 64.6 & 89 & 57.4 \\
\hline Impedes implantation & 31 & 55.4 & 68 & 68.7 & 99 & 63.9 \\
\hline Induces abortion & 1 & 1.8 & 1 & 1 & 2 & 1.3 \\
\hline Kills the spermatozoon & 9 & 16.1 & 19 & 19.2 & 28 & 18.1 \\
\hline Do not know & 10 & 17.9 & 7 & 7.1 & 17 & 11 \\
\hline Other & 6 & 10.7 & 17 & 17.2 & 23 & 14.8 \\
\hline The period of use of EC is 120 hours & 11 & 19.6 & 42 & 42.4 & 53 & 34.2 \\
\hline
\end{tabular}

There are differences in what trained providers and untrained providers know about the EC mechanism of action. $44.6 \%$ of untrained providers indicated the blocking ovulation as the EC mechanism of action as opposed to $64.6 \%$ of trained providers. Also, few providers are aware of the newest guidelines related to the timing of EC administration, which is now 120 hours. The highest percentages regarding this newest guideline were found with doctors and midwives (50\% and 41\% respectively). On the other hand, the level of knowledge of pharmacists remained low $(11.5 \%)$. Differences between trained and untrained providers persist.

Graph 2 also reveals that a large number of providers do not know that pregnancy is an exclusion criterion for use. More than half of providers did not cite pregnancy as an EC exclusion criterion ${ }^{8}$.

Graph 2: Knowledge of medical contraindications of EC use

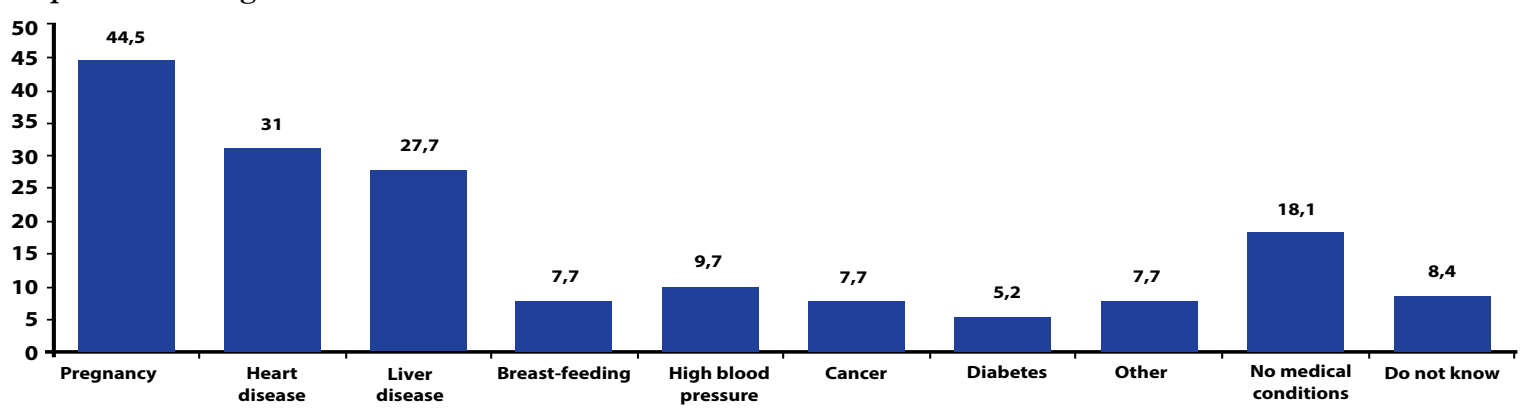

It can be noted that few providers cited cervix cancer as an EC exclusion criterion.

The study results also reveal that knowledge around EC's mechanism of action remains low amongst providers. Few of them could give correct answers as to the EC mechanism of action, the time of use, and the eligibility criteria. It is important to build providers' knowledge in this area through the organization of training sessions. 


\section{Opinions about $\mathbb{E C}$}

It should be noted that few providers equate EC practice with a form of abortion. $11 \%$ of them believe that EC would be a form of abortion.

Table 11: Percentage of providers who think EC is a form of abortion

\begin{tabular}{|c|c|c|c|c|c|c|c|c|}
\hline Professional category & \multicolumn{2}{|c|}{ Dakar } & \multicolumn{2}{|c|}{ Thiès } & \multicolumn{2}{|c|}{ Mbour } & \multicolumn{2}{|c|}{ Total } \\
\hline Midwife & 4 & 5.9 & & & & & 4 & 4.8 \\
\hline Pharmacist & 6 & 28.6 & & & 2 & 100 & 8 & 30.8 \\
\hline Counter staff & 5 & 17.9 & 1 & 50 & & & 6 & 20 \\
\hline
\end{tabular}

However, amongst pharmacists, a significant number of counter staff $(20 \%)$ and pharmacists $(30.8 \%)$ equate it with abortion. Moreover, there is still much resistance in regards to the eligibility of all women for EC use, which is contrary to national guidelines that state that all women are eligible for this method if there are no medical contraindications.

Graph 3: Distribution of providers by knowledge of EC eligibility criteria

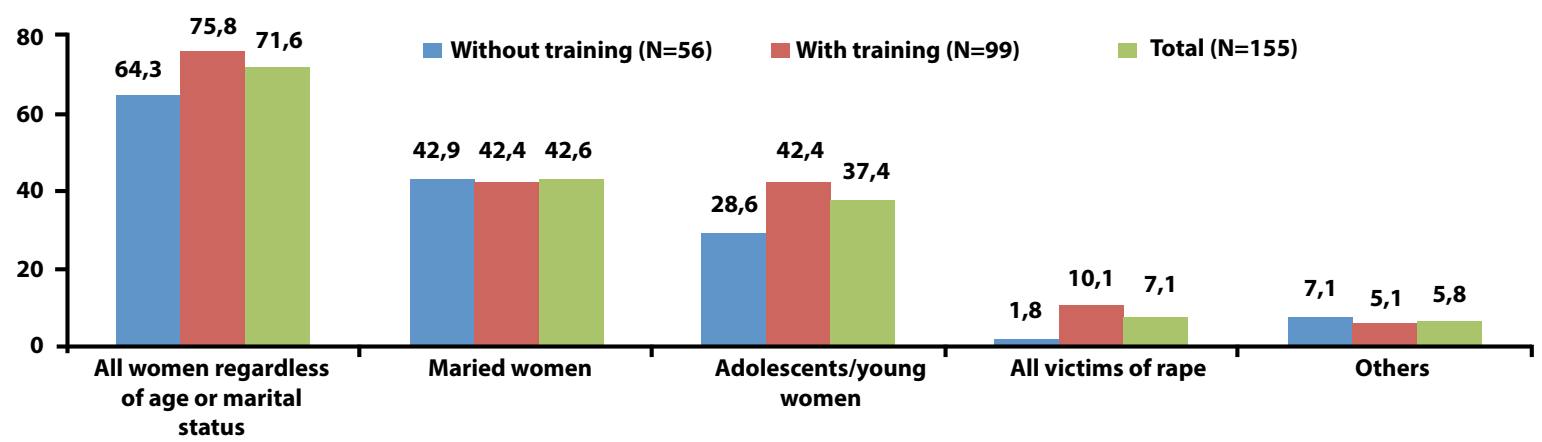

Indeed, the percentage of providers who stated that all women regardless of marital status were eligible for EC was $75.8 \%$ and $64.3 \%$ respectively for trained and untrained providers. Less than $45 \%$ of providers believe that married women and adolescents were eligible for EC.

Although a majority of providers believe that EC is a safe product, few of them stated that it should be sold without a prescription ( $42.4 \%$ and $37.5 \%$ respectively for trained and untrained providers).

Graph 4: Distribution of providers by opinions on certain conditions of EC provision

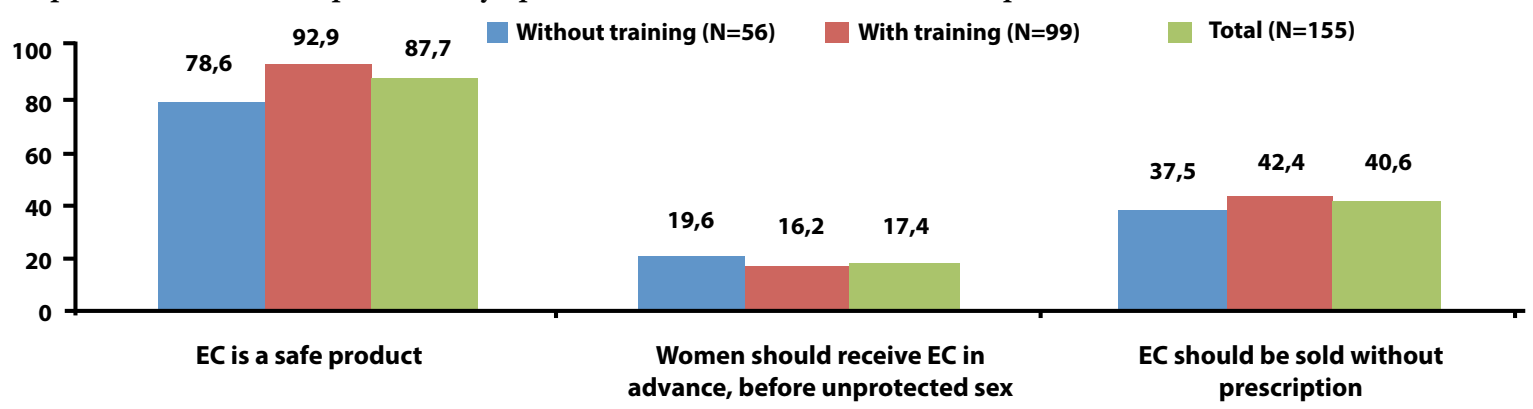

In addition, they are not in favor of providing EC to women in anticipation of unprotected sex.

Graph 5: Distribution of providers by opinions on type of providers authorized to supply EC

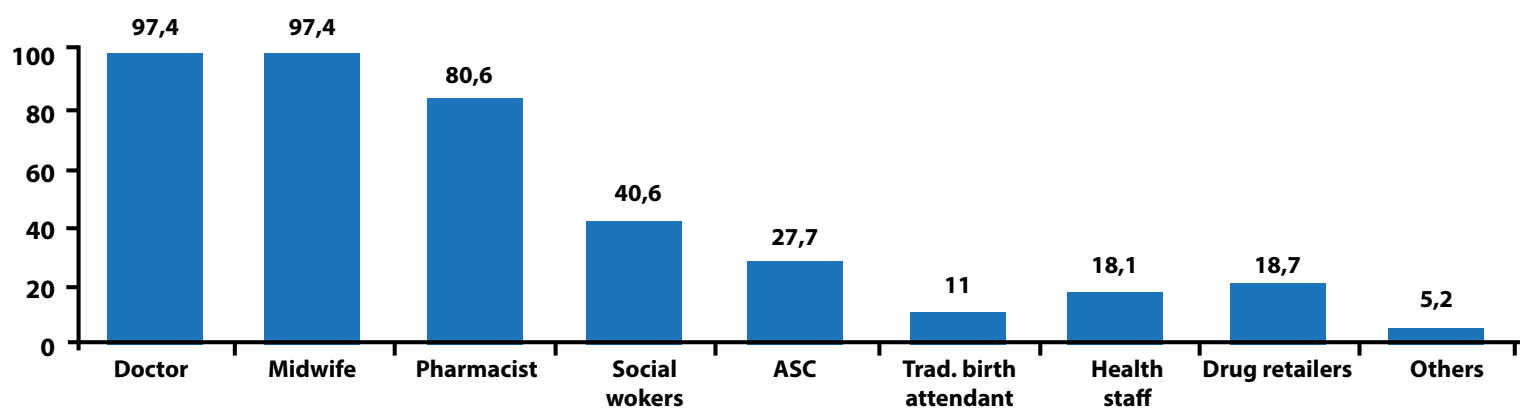

Graph 5 indicates that a vast majority of providers is in favor of EC being provided by qualified medical personnel (e.g. doctors, midwives, and pharmacists). Most of them are reluctant as to the provision by 
others besides these types of providers. Only $40.6 \%$ of providers believe that social workers should provide EC. Indeed, the percentage of providers in favor of EC being provided by community workers (e.g. community health agents, and traditional birth attendants) remains very low (less than $20 \%$ ).

Table 12: Distribution of providers by opinions on where EC should be offered

\begin{tabular}{lcc}
\hline \multirow{2}{*}{ Type de PPS } & \multicolumn{2}{c}{$\begin{array}{c}\text { Ensemble } \\
(\mathbf{N}=\mathbf{1 5 5})\end{array}$} \\
\cline { 2 - 3 } & $\mathbf{N}$ & $\mathbf{0}$ \\
\hline Hôpitaux & 148 & 95.5 \\
\hline Centres de santé & 152 & 98.1 \\
\hline Postes de santé & 147 & 94.8 \\
\hline Cases de santé & 51 & 32.9 \\
\hline Clinique privée & 126 & 81.3 \\
\hline Pharmacie & 122 & 78.7 \\
\hline Ecole & 13 & 8.4 \\
\hline Police & 6 & 3.9 \\
\hline Centre conseil Ado & 92 & 59.4 \\
\hline Autres & 11 & 7.1 \\
\hline
\end{tabular}

These findings are similar regarding where EC should be offered. Opinions are mostly in favor of conventional medical facilities (e.g hospitals, health post and centers, private clinics and pharmacies) as opposed to other non-conventional facilities such as health huts, school infirmaries, and police. The latter could enhance access to EC services for vulnerable groups such as students, rural women, and prisoners. A significant percentage of providers $(41.1 \%)$ are not in favor of EC provision in Adolescent Counseling Centers, which are place specifically reserved for that target.

Graph 6: Distribution of providers by opinion on when EC should be used

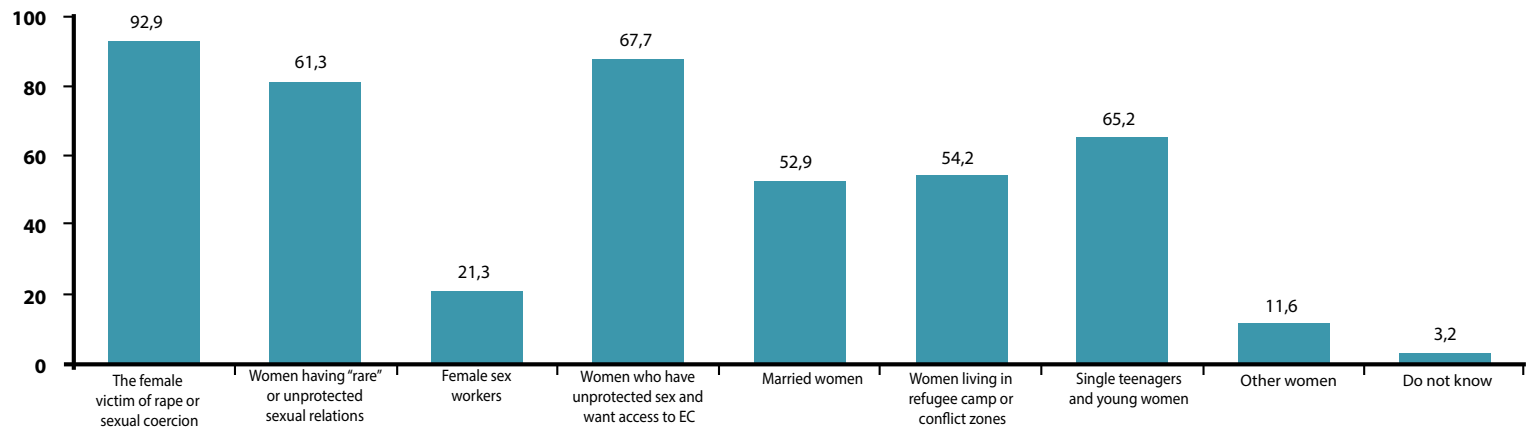

If a majority of providers are in favor of EC being provided to victims of rape and sexual abuse, and women who have unprotected sex and want access to EC, opinions are more mixed in regards to EC use by sex workers, married women, single adolescents, and women living in conflict zones (refugees).

\section{Perceptions of EC}

Providers were interviewed about their perceptions of the profile of the average EC user. More than half of providers indicated that they believe EC users are less than 30 years old. Almost $35 \%$ indicated the age range would be between 20 and 29 years old, $15 \%$ between 15 and 19 years old, and $4 \%$ at less than 15 years old. On the other hand, $29 \%$ of providers believe that women of all ages would be EC users. However, a small percentage felt that they would be older than 40 .

Table 13: Distribution of providers by opinions on age of EC users

\begin{tabular}{|c|c|c|c|c|c|c|c|c|}
\hline Ages & \multicolumn{2}{|c|}{ Dakar } & \multicolumn{2}{|c|}{ Thiès } & \multicolumn{2}{|c|}{ Mbour } & \multicolumn{2}{|c|}{ Total } \\
\hline Between 15 and 19 years & 20 & 15.5 & 4 & 25 & & & 24 & 15.5 \\
\hline Between 30 and 39 years & 16 & 12.4 & & & & & 16 & 10.3 \\
\hline 40 years and older & 3 & 2.3 & & & & & 3 & 1.9 \\
\hline Women of all ages & 34 & 26.4 & 6 & 37.5 & 5 & 50 & 45 & 29 \\
\hline
\end{tabular}

In addition, providers' opinions on repeated use were discussed. The vast majority believes that EC use should be limited. Almost $76 \%$ believe that it should not exceed four times a year. This includes almost two providers in ten who state that EC should be used only once a year and almost six providers in ten believe that EC should be used between two and four times a year. Few providers believe that EC should be used at each menstrual cycle or any time it is needed (less than two in ten providers). 
Table 14: Distribution of providers by opinions on number of times a woman can use EC per year

\begin{tabular}{lcc}
\hline & \multicolumn{2}{c}{ Total } \\
\cline { 2 - 3 } & $\mathbf{N}$ & $\mathbf{0}$ \\
\hline Once a year & 15 & 20.3 \\
\hline 2-4 times a year & 41 & 55.4 \\
\hline 5-10 times a year & 1 & 1.4 \\
\hline Once a month & 6 & 8.1 \\
\hline As often as necessary & 9 & 12.2 \\
\hline Other & 1 & 1.4 \\
\hline Do not know & 1 & 1.4 \\
\hline Total & $\mathbf{7 4}$ & $\mathbf{1 0 0}$ \\
\hline
\end{tabular}

There is a negative perception by providers towards women who use EC. Almost $70 \%$ of them believe that they run a higher risk of risky sexual behavior, will have an STI $(68 \%)$, will have multiple sexual partners (58\%) and will not use regular contraception $(57 \%)$.

Table 15: Distribution of providers by perceptions of women who use EC

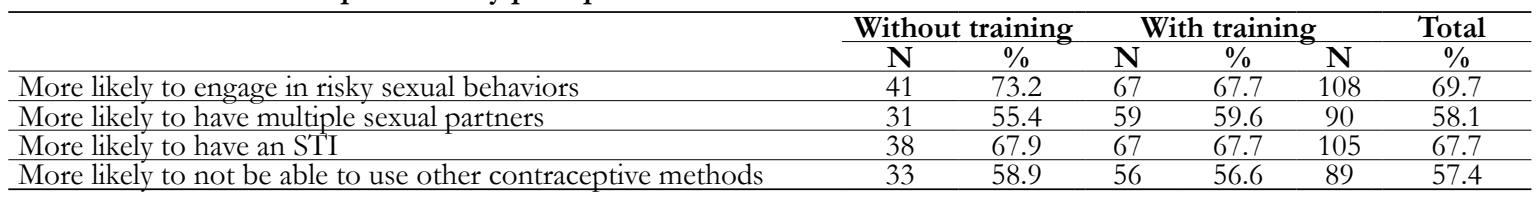

\section{EC Service Delivery}

The data in Table 16 show that while the majority of providers inform their clients of the EC mechanism of action (72\%) and how it should be used (67\%), and about FP (67\%), few of them refer clients to FP service $(28 \%)$ or to other DRH services (29\%). Almost half $(49.7 \%)$ inform clients of side effects, almost one third $(32.9 \%)$ of providers do not give FP advice.

Table 16: Distribution of providers by services normally provided to EC

\begin{tabular}{lcc} 
& & Total \\
\cline { 2 - 3 } & $\mathrm{N}$ & $\%$ \\
\hline Provides only EC pills & 52 & 33.5 \\
\hline Provides general information about EC & 92 & $\mathbf{5 9 . 4}$ \\
\hline Provides instructions on how to take EC & 104 & $\mathbf{6 7 . 1}$ \\
\hline Provides the mode of use of EC & 112 & $\mathbf{7 2 . 3}$ \\
\hline Provides information on the side effects & 77 & $\mathbf{4 9 . 7}$ \\
\hline Provides advice on family planning & 104 & $\mathbf{6 7 . 1}$ \\
\hline Provides information on STls and HIV & 83 & $\mathbf{5 3 . 5}$ \\
\hline Responds to questions and concerns & 69 & 44.5 \\
\hline Refers to family planning services & 43 & $\mathbf{2 7 . 7}$ \\
\hline Refers to other services & 45 & 29 \\
\hline Offers other services to EC clients & 11 & 7.1 \\
\hline
\end{tabular}

A vast majority of providers indicated that they normally offer Norlevo ${ }^{\circledR}$ to their clients (almost eight providers in ten).

Graph 7: Types of EC products normally provided to users

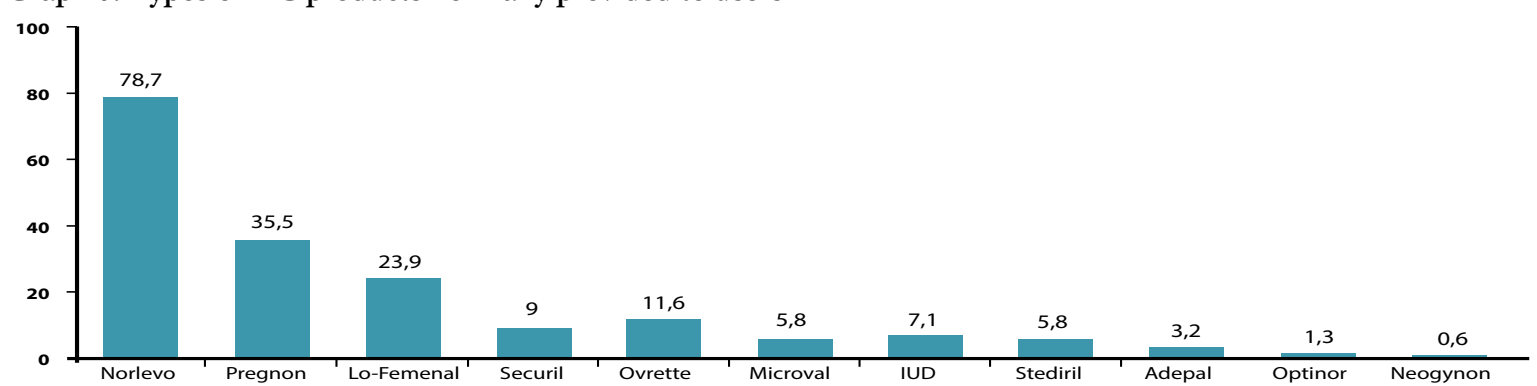

Besides Norlevo ${ }^{\circledR}$, Pregnon ${ }^{\circledR}$ is still the most offered product. As the data in Graph 7 indicates, other EC products remain scarce in routine EC provision.

According to providers, EC products usually available in public facilities were mostly Lo-Femenal (79\%), Ovrette (73\%), and IUDs (54\%). It can be deduced that EC products, specifically, are not readily available in public facilities. Pregnon ${ }^{\circledR}$ was only cited by $40 \%$ of providers and Norlevo ${ }^{\circledR}$ by only $2 \%$ of providers. It can be deduced that providers also use other options besides Pregnon. In private pharmacies, Norlevo ${ }^{\circledR}$ is cited $(98 \%)$. However, other products such as Securil and Microval are available. We note the presence of a larger variety of EC products in private clinics as the data in Graph 7 shows. This indicates that there are several options in EC provision. Other products are rare 
Graphs 8-10: Type of products available by type of SDP
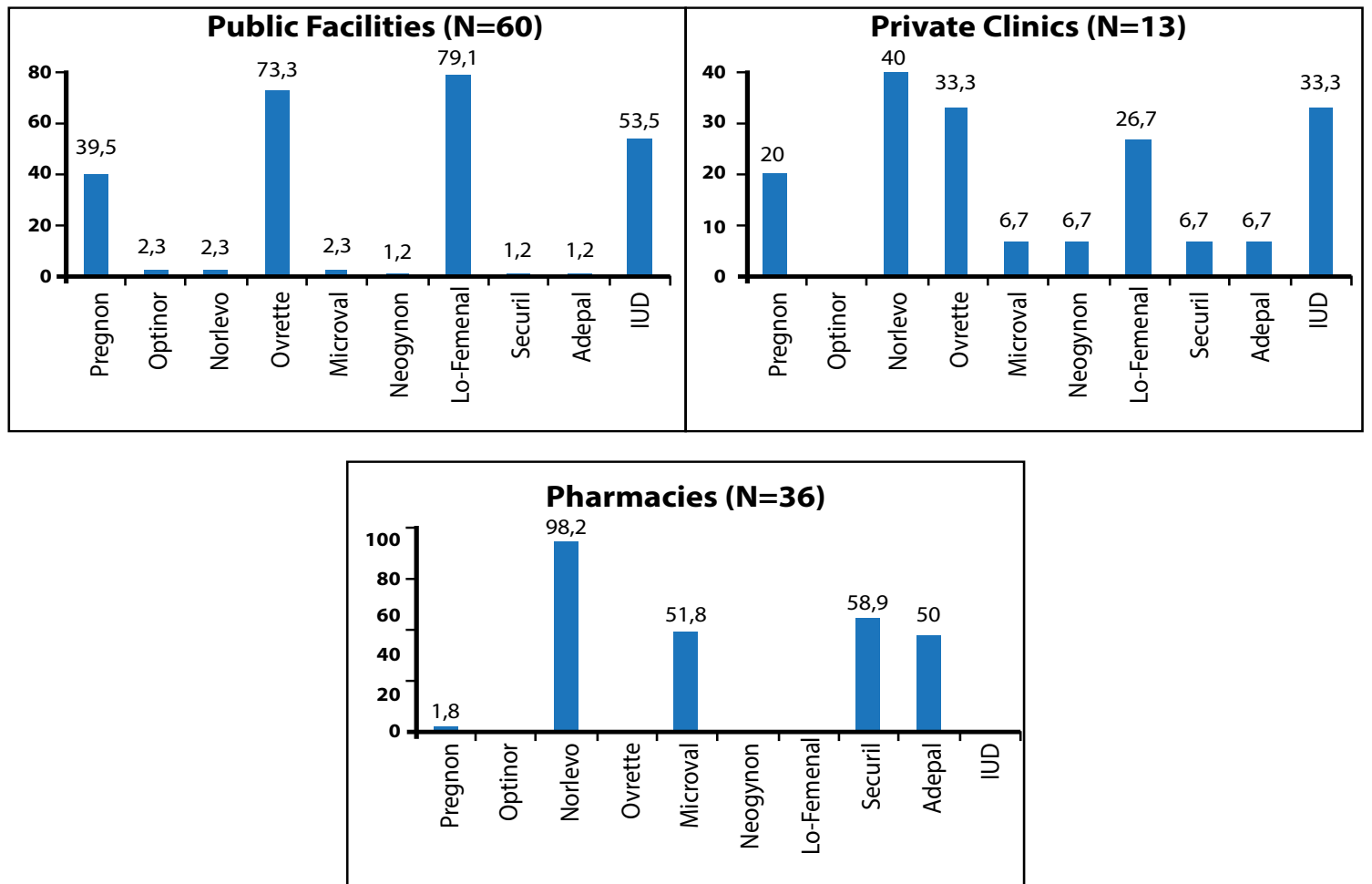


\section{Conclusion}

The KOL and provider survey results reveal that EC is an integral part of the national FP program. In fact, EC ranks high not only in policy documents, norms, and protocols regarding DRH/FP service delivery, but also in provider training documents. KOLs and providers are conscious of the importance of $\mathrm{EC}$ in the prevention of unwanted pregnancies and are in favor of EC integration in national guidelines.

However, it is evident from these results that there is an urgent need to improve EC accessibility and the quality of its services. The vast majority of KOLs and providers believe that community awareness and the popularization of the product should be the primary activities to build awareness amongst the populations, young people in particular, about the product. The information given to communities could also contribute to reduce stigma, biases, worries, and reluctance about EC use.

The persistence of these prejudices toward EC could be linked to EC's recent past in Senegal.

Its official introduction to the national system goes back less than six years. The ideas and experiences are being built now, and it takes time to change ideas and behavior. EC history in Senegal is highly dependent on FP history, which is characterized by low use of modern methods and by the weight of sociocultural pressures. However, the perspective of better acceptance of the product is open. In fact, facing the scope of sexual violence/abuse, induced abortions, and the question of women's and adolescent health rights, there are more and more decision makers and communities who wish to preserve the health and well being of certain vulnerable groups, particularly adolescents/young people and women. These factors could provide the momentum needed for EC promotion. 


\section{Recommendations}

The primary recommendations of the study are:

- Community awareness for wider product knowledge;

- Provider training;

- Establishment of a logistics management system to ensure product availability;

- Improve product affordability;

- Development of partnerships, especially through greater involvement of pharmacists;

- Development of advocacy activities with decision makers. 


\section{References}

Reproductive Health Division. Provider reproductive health training guide on emergency contraception. March 2008. 45 pp. In collaboration with Population Council \& ECafrique.

Reproductive Health Division. Study of emergency contraception in pharmacies. September 2009. 18 pp. In collaboration with Population Council \& ECafrique.

International Consortium for Emergency Contraception. The emergency contraceptive pill: Mechanism of action. May 2011. 3 pp.

Population Council. Report from the national forum on emergency contraception. November 2010. 15 pp.

Population Council. Emergency Contraception: addressing unwanted pregnancies and maternal mortality in Senegal. Fact Sheet. 2009. 2 pp. 

